\title{
The Cross Section of Expected Holding Period Returns and Their Dynamics: A Present Value Approach
}

\section{Citation}

Lyle, Matthew R., and Charles C.Y. Wang. "The Cross Section of Expected Holding Period Returns and Their Dynamics: A Present Value Approach." Journal of Financial Economics 116, no. 3 (June 2015): 505-525.

\section{Published Version}

http://www.sciencedirect.com/science/article/pii/S0304405X15000252

\section{Permanent link}

http://nrs.harvard.edu/urn-3:HUL.InstRepos:16176604

\section{Terms of Use}

This article was downloaded from Harvard University's DASH repository, and is made available under the terms and conditions applicable to Open Access Policy Articles, as set forth at http:// nrs.harvard.edu/urn-3:HUL.InstRepos:dash.current.terms-of-use\#OAP

\section{Share Your Story}

The Harvard community has made this article openly available.

Please share how this access benefits you. Submit a story.

\section{Accessibility}


H A R VAR D

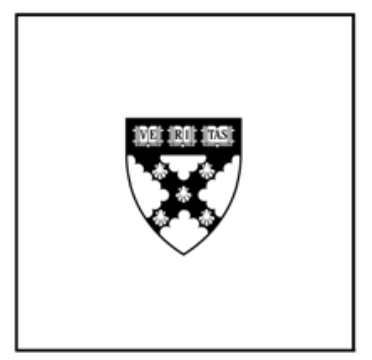

\section{The Cross Section of Expected Holding Period Returns and their Dynamics: A Present Value Approach}

Matthew R. Lyle Charles C.Y. Wang

\section{Working Paper}

13-050

June 19, 2014 


\title{
The Cross Section of Expected Holding Period Returns and their Dynamics: A Present Value Approach
}

\author{
Matthew R. Lyle \\ Kellogg School of Management
}

\author{
Charles C.Y. Wang * \\ Harvard Business School
}

\author{
June 2014 \\ Forthcoming in the Journal of Financial Economics
}

\begin{abstract}
We provide a tractable model of firm-level expected holding period returns using two firm fundamentals - book-to-market ratio and ROE - and study the crosssectional properties of the model-implied expected returns. We find that: 1) firm level expected returns and expected profitability are time-varying, but highly persistent; 2) forecasts of holding period returns strongly predict the cross section of future returns up to three years ahead. We document a highly significant predictive pooled regression slope for future quarterly returns of 0.86 , whereas the popular factor-based expected return models have either an insignificant or a significantly negative association with future returns. In supplemental analyses, we show that these forecasts are also informative of the time-series variation in aggregate conditions: 1) for a representative firm, the slope of the conditional expected return curve is more positive in good times, when expected short-run returns are relatively low; 2) the model-implied forecaster of aggregate returns exhibits modest predictive ability. Collectively, we provide a simple, theoretically-motivated, and practically useful approach to estimating multi-period ahead expected returns.
\end{abstract}

Keywords: Expected returns, discount rates, holding period returns, fundamental valuation, present value.

JEL: G12, G17, G10

${ }^{*}$ Lyle can be reached at m-lyle@kellogg.northwestern.edu and Wang can be reached at charles.cy.wang@hbs.edu. For helpful comments and suggestions, we are grateful to Maria Ogneva (FARS discussant), Steve Lim (AAA discussant), Steve Penman, an anonymous referee, Bob Magee, Akash Chattopadhyay, Ryan Buell, Daniel Malter, Tatiana Sandino, Pian Shu, and participants at the 2013 FARS conference. We also thank Kyle Thomas for excellent research assistance. 


\section{Introduction}

The ample evidence that expected equity returns are time-varying (Cochrane, 2011) has significant implications on how investors should make capital allocation decisions when they face different investment horizons. ${ }^{1}$ In particular, capturing the dynamics in expected returns is critical in assessing the holding period returns of investment opportunities over different horizons, which can guide investors in tailoring their portfolios to match their desired investment horizons. For example, investors who allocate their capital intertemporally must make projections of firm-level expected holding period returns in order to construct optimal portfolios. Ignoring the dynamics of expected returns - such as by assuming that expected returns are constant across time for a given firm - can lead to poor capital allocation decisions and as shown by Ang and Liu (2004) significant equity valuation errors.

Despite its importance, there is not yet a solution for obtaining time-varying expected holding period returns on equity at the firm level that can be easily applied to the cross section of firms. Popular firm-level expected returns produced by the traditional CAPM and the Fama and French (1993) three-factor model, or the more recent proxies suggested by the implied cost of equity capital literature implicitly assume constant expected returns.

Our paper fills a void in the literature, and contributes by providing a theoreticallymotivated, parsimonious, and easily-implementable model of expected holding period returns over arbitrary horizons. The model is derived from the present value approach of Vuolteenaho (2002) with a valuation equation similar to the popular Ohlson (1995) residual income model, but extended to allow for dynamic expected returns.

We make two key assumptions. First, building on prior research, we assume that both

\footnotetext{
${ }^{1}$ This paper uses the terms expected rates of stock returns, expected returns, cost of capital, and discount rates interchangeably.
} 
expected stock returns and expected ROE are mean-reverting. Second, we assume that in the long run expected returns and expected ROE converge, or, stated differently, a firm's ability to generate profits over and above its cost of capital (abnormal profitability) will be eroded by competition over time. These lead to a parsimonious solution for estimating the expected holding period returns over arbitrary horizons, an approach that can be easily applied to the cross section of firms using regressions of historical returns on two firm fundamentals: the book-to-market (BM) ratio and return on equity (ROE).

Our approach relates to the recent line of literature that utilizes the present value relation to study expected returns (e.g., Ang and Bekaert, 2007; van Binsbergen and Koijen, 2010; Campbell and Thompson, 2008; Cochrane, 2008; Ferreira and Clara, 2011; Kelly and Pruitt, 2013; Lettau and Ludvigson, 2005; Lettau and Van Nieuwerburgh, 2008; Pástor, Sinha, and Swaminathan, 2008). Whereas the literature has been focused on forecasting aggregate returns (at the market or portfolio levels), we focus on firm-level expected returns and their performance in predicting the cross section of future returns.

Also related to our study is the recent line of literature which has begun to study the prices and risk premiums of the term structure of dividend strips (e.g., van Binsbergen, Brandt, and Koijen, 2012; van Binsbergen, Hueskes, Koijen, and Vrugt, 2013; Lettau and Wachter, 2007). While related, ours is devoted to studying the expected returns from holding equity over different horizons. Further, a central theme in the term structure literature is the use of forward looking market based prices (such as the value of dividend strips, or bonds), our paper differs here since we derive holding period returns estimates based on historical realized returns and accounting data and do not require instruments such as dividend strips to form projections.

Our baseline implementation of the model uses BM and ROE constructed using quarterly financial statements to forecast holding period returns in quarterly intervals. We study the cross-sectional properties of the model-implied proxies of expected holding pe- 
riod returns and document that they exhibit significant ability in predicting the cross section of future holding period returns up to 3-years ahead. In out-of-sample tests, which range from 1986 to 2013, our expected return estimates predict the cross section of future returns with a regression slope coefficient for 3-, 12-, 24-, and 36-month ahead log returns of $0.86,0.72,0.60$, and 0.52 , respectively, where all coefficients are significant at the $1 \%$ level. 3 -month ahead proxies are especially reliable, as the regression slope is statistically no different from 1 and the intercept is no different from 0 , consistent with the behavior of true expected returns. Portfolio sorts using these proxies also yield a strong monotonic relation with future returns: going long the top decile and short the bottom decile of 3-, 12-, 24-, and 36-month expected return firms produce spreads future returns of $5.48 \%, 15.42 \%, 30.44 \%$, and $46.32 \%$, respectively, all significant at the $1 \%$ level.

These results are robust to various implementations of the model: for example, by implementing instrumental variables estimation or using annual financial statement data. In contrast to our model-implied proxies, we find that firm-level expected returns produced by the popular factor-based models (i.e., CAPM, Fama and French, 1993 three-factor model, and a four factor model that augments the previous with a momentum factor) do not positively predict the cross section of future returns. Overall, our firm-level proxies are far more reliable than the factor-based alternatives.

These empirical findings make several contributions. First, we contribute methodologically by providing a fundamentals-based model that can forecast the cross section of stock returns out-of-sample and over different horizons. This builds on the work of Ang and Liu (2004), who developed a conditional CAPM model to discount portfolio-level cash flows at different horizons. To our knowledge, our paper and that of Callen and Lyle (2011) provide the only empirical methods for obtaining the firm-level multi-period ahead expected returns forecasts. However, unlike the work of Callen and Lyle (2011), who estimate firm-level expected holding period returns implied by option contracts that are 
limited by the existence and liquidity of contracts of different expirations, our methodology uses accounting data and is easily applied to the cross section of firms. Moreover, our firm-level proxies are particularly useful in light of the observation that CAPM and other common factor-based models can be difficult to apply over different investment horizons - unless one assumes that factor loadings and premiums are flat - coupled with the finding that these models do not reliably and positively predict out-of-sample future returns. Our solution is a more useful input to inform investors' capital allocation decisions.

Second, whereas the asset pricing literature has mostly focused on the performance of aggregate predictive regressions (e.g., Welch and Goyal, 2008; Campbell and Thompson, 2008) and, more generally, the out-of-sample predictive ability of aggregate return forecasters (e.g., van Binsbergen and Koijen, 2010; Kelly and Pruitt, 2013), there is relatively little evidence on the out-of-sample predictive ability and reliability of firm-level expected returns produced by cross-sectional regressions. We contribute new evidence to this end and show that cross-sectional-regression based estimates of firm-level expected returns are reliably associated with the cross section of future returns.

Moreover, our results show that reliable proxies of firm-level expected holding period returns can be obtained using only realized returns, the BM ratio, and ROE. This finding contributes to the recent literature focused on the estimation of firm-level expected returns, such as the implied cost of capital literature, which has produced a plethora of proxies that are not only fraught with implementation issues but also have not been found to be reliable (e.g., Easton and Monahan, 2005). ${ }^{2}$ Moreover, while recent research has

\footnotetext{
${ }^{2}$ Proxies offered by this literature, (e.g., Claus and Thomas, 2001; Gebhardt, Lee, and Swaminathan, 2001; Easton, Taylor, Shroff, and Sougiannis, 2002; Easton, 2004; Gode and Mohanram, 2003) typically require solving complicated non-linear equations which can produce multiple solutions, the choice of which lacks theoretical guidance. Furthermore, these measures often rely on analysts' biased forecasts of future earnings (Hou, Van Dijk, and Zhang, 2012; Mohanram and Gode, 2012), are sensitive to the estimation of long-term growth estimates (e.g., Easton et al., 2002; Nekrasov and Ogneva, 2011), and assume constant expected returns, all of which lead to noisy measures of expected equity returns (e.g., Hughes, Liu, and Liu, 2009; Wang, 2013).
} 
begun to examined the link between firm characteristics and the cross section of future returns, these papers use ad hoc models and empirically inspired predictors (e.g., Lee, So, and Wang, 2012 and Lewellen, 2013) and their methods are not easily adapted to accommodate muti-period ahead forecasts (e.g., Lyle, Callen, and Elliott, 2013). Our approach is guided by a fully-solved valuation model involving only two determinants, and the resultant proxies are reliable.

We also contribute further evidence on the open question on the persistence in expected returns, a key structural parameter of our model that is recovered in the estimation. Whereas Kelly and Pruitt (2013) argue that expected annual returns are far less persistent $(\mathrm{AR}(1)$ parameter of $<0.3)$ than those documented in prior literature $(\mathrm{AR}(1)$ parameters between 0.91 to 0.94 ), our estimates are closely in line with the latter, despite differences in estimation methodologies.

Finally, though the main focus of the paper is on the cross-sectional properties of the firm-level estimates of expected returns implied by BM and ROE, in supplemental analyses we also examine how the model performs in capturing the time-series variations in aggregate conditions. We find that, for the representative firm, the slope of the conditional expected return curve (i.e., the difference between annualized long-horizon and short-horizon holding period returns) tracks economic conditions. This slope is more positive during normal times or times of economic expansion, when expected short-run returns are relatively low; during times of economic distress or uncertainty, on the other hand, this difference becomes less positive, as uncertainty and risk in the short-run are elevated. Moreover, we show that the model produces a forecaster of aggregate returns that exhibits a modest predictive ability of 3-month ahead returns, with a predictive $R^{2}$ of $0.62 \%$. A comparison to the state-of-the-art forecaster proposed by Kelly and Pruitt (2013) suggests that as more quarterly fundamental data becomes available, the performance of this simple aggregate forecaster can be expected to improve. 
Thus, we contribute to the literature by offering a model and methodology for estimating expected returns that is not only useful in forecasting the cross section of firm-level returns but also the time-series variation in aggregate returns. To our knowledge, no other model or methodology has been shown to exhibit evidence of predictive ability in both of these dimensions. For example, sophisticated forecasters like the ones proposed by van Binsbergen and Koijen (2010) or Kelly and Pruitt (2013) could not be implemented for the cross section of firms given the extensive time-series data needed to perform their filtering algorithms; and although they could be applied to forecast the portfolio level returns in time series, it is unclear whether differences between portfolio-level expected returns forecast differences in future returns. ${ }^{3}$

The remainder of the paper is organized as follows. Section 2 presents the model for valuing stock prices and estimating expected returns. Section 3 discusses the estimation of the model and presents our empirical findings. Section 4 discusses the robustness tests and supplemental analyses. Section 5 concludes the paper. All proofs are detailed in the Appendix.

\section{The Model}

We derive a stock valuation model based on the log-linearization of Vuolteenaho (2002). The linearization approach allows for firm-specific log returns to be expressed in terms of log BM ratio and log ROE, assuming the clean surplus relation holds. Based on this decomposition, realized log returns for a firm $(i)$ can be written as

$$
r_{i, t+1}=b m_{i, t}-k_{1} b m_{i, t+1}+\operatorname{roe}_{i, t+1},
$$

\footnotetext{
${ }^{3}$ Forecasts can perform well in the time-series but not in the cross section, for example, if there are portfolio-specific biases that are constant but do not preserve the rank ordering of portfolio-level expected returns.
} 
where, $r_{i, t+1}=\ln \left(\frac{S_{i, t+1}+D_{i, t+1}}{S_{i, t}}\right), b m_{i, t}=\ln \left(\frac{B_{i, t}}{S_{i, t}}\right)$ is the $\log$ BM ratio where $B_{i, t}\left(S_{i, t}\right)$ is the book (market) value of equity, $D_{i, t+1}$ are dividends; roe $e_{i, t+1}=\ln \left(1+\frac{E_{i, t+1}}{B_{i, t}}\right)$ is $\log$ ROE where $E_{i, t+1}$ represents firm earnings for period $t+1$; and $k_{1}$ is a cross-sectional constant close to one. From here, the log BM ratio can be conveniently expressed in terms of expected log returns and expected log $\mathrm{ROE}^{4}$

$$
b m_{i, t}=\sum_{j=1}^{\infty} k_{1}^{j-1}\left(\mathbb{E}_{t}\left[r_{i, t+j}\right]-\mathbb{E}_{t}\left[\text { roe }_{i, t+j}\right]\right) .
$$

We assume in addition that expected log returns, $\mathbb{E}_{t}\left[r_{i, t+1}\right] \equiv \mu_{i, t}$, and expected log $\mathrm{ROE}, \mathbb{E}_{t}\left[\right.$ roe $\left._{i, t+1}\right] \equiv h_{i, t}$, are time-varying and mean-reverting. For tractability, we assume that both follow $\mathrm{AR}(1)$ processes with a common mean,

$$
\begin{gathered}
\text { Expected Log Returns: } \mu_{i, t+1}=\mu_{i}+\kappa_{i}\left(\mu_{i, t}-\mu_{i}\right)+\xi_{i, t+1} \text {, and } \\
\text { Expected Log ROE: } h_{i, t+1}=\mu_{i}+\omega_{i}\left(h_{i, t}-\mu_{i}\right)+\epsilon_{i, t+1},
\end{gathered}
$$

where $\omega_{i}$ and $\kappa_{i}$ represent the levels of persistence in expected log returns and ROE, respectively; $\mu_{i}$ represents the long-run average expected log return as well as the long-run expected log ROE; and $\left(\xi_{i, t+1}, \epsilon_{i, t+1}\right)$ are expected returns and expected ROE innovations assumed to be IID with mean zero and finite second moment. Under the AR(1) structure, $\log$ BM ratio can be simplified as

$$
b m_{i, t}=\frac{1}{1-k_{1} \kappa_{i}}\left(\mu_{i, t}-\mu_{i}\right)-\frac{1}{1-k_{1} \omega_{i}}\left(h_{i, t}-\mu_{i}\right) .
$$

It follows that in the long run book values and market values are expected to converge to the same mean, consistent with mark-to-market accounting. ${ }^{5}$

\footnotetext{
${ }^{4}$ Details of the derivation are in Appendix A.

${ }^{5}$ This is consistent with Vuolteenaho (2002), whose log-linearization expands around a common point for both dividend-to-price and dividend-to-book. If we take this expansion point as the unconditional mean in the ratios, it implies that $E\left[\log \left(\frac{D}{S}\right)\right]=x=E\left[\log \left(\frac{D}{B}\right)\right]$ or $E[\log (S)]=E[\log (B)]$.
} 
The assumption that expected returns are $\mathrm{AR}(1)$ or mean-reverting is common in modeling interest rates (e.g., Cochrane, 2001; Duffie, 2001) as well as in modeling expected returns of equities (Campbell, 1991; van Binsbergen and Koijen, 2010; Pástor and Stambaugh, 2012; Wang, 2013). Our assumption of mean-reverting expected ROE follows Freeman, Ohlson, and Penman (1982), Lee, Myers, and Swaminathan (1999), Gebhardt et al. (2001), and Dichev and Tang (2009). The common mean assumption is implicit in the Vuolteenaho (2002) log-linearization and is, in spirit, similar to the motivation for the dynamics of Ohlson (1995), who assumes long-run abnormal earnings converge to zero due to competition. However, we acknowledge the possibility that this assumption may not be empirically supported as features of accounting systems, such as conservative accounting, may result in expected ROEs that differ from the expected rate of returns in the long-run even if firms do not earn economic rents (e.g., Cheng, 2005; Feltham and Ohlson, 1995, 1996; Penman and Zhang, 2002; and Zhang, 2000). While we may be potentially trading off parsimony for realism, to the extent that the difference between expected log ROE and expected log returns converges to a non-zero constant in the long run, it is unclear how or to what extent our assumption might bias our model's ability to explain realized returns. Ultimately, we test to what extent the model's implied proxies of expected log returns predict the cross section of future returns.

\subsection{Stock Prices}

Given the dynamics of expected log returns and expected log ROE modeled above, the log market value of equity $\left(s_{i, t}\right)$ can be parsimoniously expressed as

$$
s_{i, t}=b_{i, t}+\alpha_{1}\left(h_{i, t}-\mu_{i}\right)-\alpha_{2}\left(\mu_{i, t}-\mu_{i}\right)
$$


where $\alpha_{1}=\frac{1}{1-\omega_{i} k_{1}}$ and $\alpha_{2}=\frac{1}{1-\kappa_{i} k_{1}}$. This equation says that firm value can be written in a form similar to that of the seminal Ohlson (1995) model. Firm values are anchored by book value plus a linear combination of "abnormal" expected log ROE and "abnormal" expected log returns.

We expect the coefficient $\alpha_{1}$ to be positive because, all else equal, higher levels of expected profitability should imply higher prices, and we expect $\alpha_{2}$ to be positive because, all else equal, higher levels of expected returns lower equity values. AR(1) persistence parameters less than unity would imply that both $\alpha_{1}>0$ and $\alpha_{2}>0$.

This closed form solution for stock prices also allows for an analysis of the the potential (mis)valuation effects of assuming constant expected rates under dynamic expected returns. In particular, if long-run expected returns are used, an assumption that reflects the common practice of applying the long-run average returns in valuation models, then the pricing errors arising from assuming constant expected returns can be expressed as:

$$
E R R O R=\left|\frac{S_{i, \text { true }}-S_{i, \text { wrong }}}{S_{i, \text { true }}}\right|=\left|1-\exp \left(\alpha_{2}\left(\mu_{i, t}-\mu_{i}\right)\right)\right|
$$

where $S_{i, \text { true }}$ is the price of the stock with time-varying expected returns and $S_{i, \text { wrong }}$ is the stock valuation assuming a constant expected returns. Clearly, the smaller the difference between short-run and long-run expected returns, the smaller the valuation error. Moreover, the lower the persistence in conditional expected returns - thus quicker reversion to the long-run mean - the smaller the valuation error. Though an investigation into these mispricing effects is beyond the scope of our paper, we believe this to be an important area of research in the valuation literature and provide here a simple analytical framework. 


\subsection{Expected Holding Period Returns}

Rearranging equation (6) and solving for $\mu_{i, t}$, expected returns over the next period can be expressed as

$$
\mu_{i, t}=\mu_{i}+\frac{1}{\alpha_{2}}\left[b m_{i, t}+\alpha_{1}\left(h_{i, t}-\mu_{i}\right)\right] .
$$

In this setting, expected log returns can be determined by a constant, the log BM ratio, and expectations of log ROE. Intuitively, higher levels of BM and higher expectations about ROE imply higher expected returns.

Given the dynamics of expected returns from equation (3) and conditional expected returns over the next period from equation (8), a full description of expected holding period returns over arbitrary future horizons can be expressed in closed form:

$$
\sum_{j=1}^{T} \mathbb{E}_{t}\left[r_{i, t+j}\right]=\sum_{j=1}^{T} \mathbb{E}_{t}\left[\mu_{i, t+j-1}\right]=\mu_{i} T+\frac{\left(1-\kappa_{i}^{T}\right)}{1-\kappa_{i}} \frac{1}{\alpha_{2}}\left[b m_{i, t}+\alpha_{1}\left(h_{i, t}-\mu_{i}\right)\right]
$$

This equation implies that the average expected holding period return on equity over time $T\left(\frac{1}{T} \sum_{j=1}^{T} \mathbb{E}_{t}\left[\mu_{i, t+j-1}\right]\right)$ consists of a long-run average return component $\left(\mu_{i}\right)$ and a short-run average return component $\left(\frac{1}{T} \frac{\left(1-\kappa_{i}^{T}\right)}{1-\kappa_{i}} \frac{1}{\alpha_{2}}\left[b m_{i, t}+\alpha_{1}\left(h_{i, t}-\mu_{i}\right)\right]\right)$. As the holding period horizon increases, average holding period returns converge to long-run expected returns.

The simplicity of the above equation reveals this model's appeal. Unlike other adhoc methods for estimating the expected rate of returns, this model is parsimonious and grounded in the present value approach. It is linear in only two firm fundamental characteristics and allows for relatively straight forward estimation of firm level holding period returns over various horizons. Finally, this model overcomes some important limitations that have plagued the implied cost of capital models: 1) they assume constant discount rates; 2) they rely on ad-hoc terminal growth estimates; and 3) their estimation 
often requires solving non-linear equations via numerical methods that may or may not converge, or may converge to multiple solutions. Our model is fully dynamic, allows for the simultaneous estimation of long-term rates of returns on the book value and market value of equity, and its parameters are easy to compute.

\section{Model Calibration and Main Empirical Tests}

In this section we describe the process of estimating equation (8), including the data requirements and key inputs, to compute the model-implied estimates of expected holding period returns. We then present our main empirical tests to assess the cross-sectional performance of these estimates.

\subsection{Data and Calibration}

To estimate the model parameters empirically, we assume the following relations between realized and expected log returns and log ROE:

$$
\begin{aligned}
r_{i, t+1} & =\mu_{i, t}+\eta_{i, t+1}, \\
\operatorname{roe}_{i, t+1} & =h_{i, t}+\nu_{i, t+1},
\end{aligned}
$$

where $\mu_{i, t}$ and $h_{i, t}$ are expected log returns and log ROE, respectively, and the noise terms $\eta_{i, t+1}$ and $\nu_{i, t+1}$ are mean zero and independently distributed. Substituting into equation (8) and applying the AR(1) assumption to expected log ROE yields the following estimable equation relating one-period ahead realized log returns to current log BM ratios and $\log \mathrm{ROE}$,

$$
r_{i, t+1}=\underbrace{\mu_{i}\left(1-\omega_{i} \frac{\alpha_{1}}{\alpha_{2}}\right)}_{\beta_{0}}+\underbrace{\left(1-\kappa_{i} k_{1}\right)}_{\beta_{1}} b m_{i, t}+\underbrace{\left(\omega_{i} \frac{1-k_{i} k_{1}}{1-\omega_{i} k_{1}}\right)}_{\beta_{2}} r o e_{i, t}+\zeta_{i, t+1},
$$


where $\beta_{1}=\frac{1}{\alpha 2}, \beta_{2}=\omega_{i} \frac{\alpha_{1}}{\alpha_{2}}$, and $\zeta_{i, t+1}=\frac{\alpha_{1}}{\alpha_{2}}\left(\varepsilon_{i t}-\omega_{i} \nu_{i, t}\right)+\eta_{i, t+1}$.

To estimate (12), we match return and price data from The Center for Research in Security Prices (CRSP) with financial statement data from Compustat. In matching the data to the model, we needed to choose a frequency with which expected returns and expected ROE evolves according to the assumed dynamics. Our main empirical analysis uses quarterly data - i.e., expected quarterly returns and ROE follow $\mathrm{AR}(1)$ - since this represents the highest frequency with which ROE and other accounting data is realized. In light of this, our implementation of this model, which incorporates dynamic expected ROE, utilizes quarterly financial statements and makes forecasts of holding period returns on a quarterly basis.

Specifically, at the end of March, June, September, and December of each calendar year we match future delisting-adjusted quarterly returns (following Beaver, McNichols, and Price, 2007) over to the most recently available quarterly financial statement data from Compustat. Financial statement data are considered publicly available if the earnings for a particular fiscal period have been announced (Compustat variable $R D Q) .{ }^{6}$ Combining the publicly available quarterly financial statement data with end-of-quarter market prices, we construct the log BM ratio $\left(b m_{i, t}\right)$ and $\log \operatorname{ROE}\left(r_{0 e_{i, t}}\right)$. Since quarterly financial statements are only available starting at the end of 1970, we construct $b m_{i, t}$ and $r o e_{i, t}$ and match them to future quarterly log returns starting from March 1971 and ending in September 2013.

We make forecasts of expected future log returns on a quarterly basis, at the end of each calendar year quarter, and calibrate the model by estimating equation (12) through pooled regressions estimated at the Fama and French (1997) 48 industry level, using

\footnotetext{
${ }^{6}$ More specifically, at the time of the forecast, we use the most recent publicly available book values, earnings, and dividends from the set of financial statement data for which earnings were most recently announced. For those firms with missing $R D Q$ values in Compustat we assume an earnings announcement date that is 3 months from the fiscal quarter end. Our results are qualitatively unchanged by conducting the empirical analysis on the subset of firms with non-missing $R D Q$ values.
} 
historical realized log quarterly returns, log BM ratios, and log ROE to avoid look-ahead bias. $^{7}$

Implicit here are the assumptions that: 1) expected log quarterly returns and expected log quarterly ROE follow $\mathrm{AR}(1)$ processes with a common long-run mean; and 2) the model parameters are industry-specific and may be time-varying. ${ }^{8}$ These industry-specific assumptions follow from the intuition that over time firms tend to become more like their industry peers (e.g., Gebhardt et al., 2001) and that any abnormal expected ROE (in excess of expected returns) should tend to erode over time as a result of industry-level competition. ${ }^{9}$

These industry-specific parameters are easily recovered from the estimated coefficients of $(12):{ }^{10}$

$$
\begin{aligned}
\kappa & =\left(1-\beta_{1}\right) / k_{1}, \\
\mu & =\beta_{0} /\left(1-\beta_{2}\right), \\
\omega & =\frac{\beta_{2} / \beta_{1}}{1+\left(\beta_{2} / \beta_{1}\right) k_{1}} .
\end{aligned}
$$

A few caveats with the estimation of these model parameters are worth mentioning. First, consistent estimation of $(\kappa, \mu, \omega)$ follows from the consistent estimation of $\left(\beta_{0}, \beta_{1}, \beta_{2}\right)$. This is a non-trivial result that follows from Slutsky's Theorem (Hayashi, $2000)$ and the continuity of the function $f:\left(\beta_{0}, \beta_{1}, \beta_{2}\right) \mapsto(\kappa, \mu, \omega)$. Second, for purposes of constructing expected future log returns, explicit estimates of $\omega$ are unnecessary; in

\footnotetext{
${ }^{7}$ For example, to make a forecast at the end of June 2010 we use quarterly realized log returns up to June 30, 2010 and observable quarterly $b m_{i, t}$ and $r o e_{i, t}$ up to March 30, 2010.

${ }^{8}$ Note that estimation of equation (12) requires expected log returns, expected log ROE, and log BM ratio to be stationary, a property that follows from our mean-reversion assumptions on the first two series.

${ }^{9} \mathrm{We}$ also note that the estimation of parameters by industry is common in return regressions (e.g., Callen and Segal, 2004; Callen, Hope, and Segal, 2005).

${ }^{10}$ The value of $k_{1}$ is usually assumed to be around 0.97 , but its value appears to have little impact on empirical results for values in the range of 0.95 to 1 (e.g., Callen and Segal, 2010).
} 
fact, for constructing expected one-quarter ahead log returns, explicit estimates of both $\omega$ and $\kappa$ are unnecessary. Third, we winsorize $\operatorname{AR}(1)$ parameter estimates at 0.9999 and the expected long-run return estimates at 0.3 or -0.3 . Finally, although we winsorize the estimated model parameters, for purposes of constructing expected future log returns we use raw estimates of $\left(\alpha_{1}, \alpha_{2}\right)$.

In our primary tests we use a training (or burn-in) sample consisting of 60 quarters of data, from 1971Q1 to 1985Q4, for each industry. Therefore, our out-of-sample forecasting begins at the end of March 1986. ${ }^{11}$ We use a "cumulative" window approach, or recursive estimation, in that all available historical data are used to estimate equation (12) in order to form forecasts of expected log returns. However, in untabulated robustness tests all the results of our paper are qualitatively similar when we use a rolling, 60-quarter window estimation approach. Finally, to mitigate the influence of outliers, we winsorize the regressors at the top and bottom $0.5 \%$ in each regression.

\subsection{Summary Statistics}

We begin by estimating the model using quarterly data via OLS, which has the appeal of being simple and efficient. ${ }^{12}$ Table 1 reports summary statistics on the median values of the industry-level estimates of the coefficients in equation (12) and the implied model parameters. Panel B reports the time-series medians for each industry, and Panel A reports distributional summary statistics of Panel B. The mean (median) coefficient on log $\mathrm{BM}$ and $\log \mathrm{ROE}$ are 0.0263 (0.0251) and 0.2695 (0.2323), respectively, whereas the mean (median) estimate of the constant coefficient is 0.0074 (0.0091). We find that, on average for a given industry, both expected returns and expected ROE are highly persistent, with

\footnotetext{
${ }^{11}$ Though the choice of burn-in period is ad-hoc, we believe it is reasonable in terms of providing a sufficiently large training sample and a sufficiently representative out-of-sample period. Nevertheless, as we discuss and show below, our results are robust to different burn-in period choices.

${ }^{12} \mathrm{As}$ we note in the robustness test section below, this method of estimation may produce biased coefficients.
} 
average (median) AR(1) parameters of 0.9834 (0.9847) and 0.9036 (0.9244), respectively. The variation in the industry median persistence in expected returns is relatively small, with a standard deviation of 0.0096, compared to the variation in the persistence of the expected $\log$ ROE, with a standard deviation of 0.0616 and a comparably larger interquartile range.

Overall, these persistence estimates add to the empirical evidence on the persistence of expected returns. Unlike Kelly and Pruitt (2013) who argue that expected return persistence is substantially lower $(<0.3)$ than what has been documented in prior literature, our estimates are closely in line with the latter. For example, van Binsbergen and Koijen (2010) obtained an annual persistence parameter of 0.932 for the expected one-year ahead market return, which is close to the our annualized mean quarterly persistence parameter of $0.9834^{4} \approx 0.9352$

Using the estimated coefficients and implied model parameters $\left(\hat{\beta}_{1}, \hat{\beta_{2}}, \hat{\mu}, \hat{\kappa}\right)$ we form expectations for each firm, conditional on currently available data, of holding period returns following

$$
\sum_{j=1}^{T} \hat{\mu}_{t+j-1}=\hat{\mu} T+\frac{\left(1-\hat{\kappa}^{T}\right)}{1-\hat{\kappa}}\left[\hat{\beta}_{1} b m_{t}+\hat{\beta}_{2}\left(\text { roe }_{t}-\mu\right)\right] .
$$

Specifically, at the end of each calendar quarter we construct forecasts of 1-, 4-, 8-, and 12-quarter-ahead holding period returns using the most recently available historically estimated parameters to avoid look-ahead bias.

Table 2 Panel A reports the time-series average of the cross-sectional distributional summary statistics for the estimated expected log returns over different horizons, the implied long-term expected quarterly log return, the difference between the long-term and 1-quarter ahead expected log (annualized) returns, and the difference between the 4-quarter and 1-quarter ahead expected log (annualized) returns. For comparison, Table 
2 Panel B reports the time-series average of the cross-sectional distributional summary statistics for the different horizons' of realized log returns.

Comparing the mean expected returns to that of the mean realized returns over different horizons suggests that our expected return proxies map well into to future average realized returns. For example mean expected returns (realized) returns are -0.0070 ($0.0156),-0.0257(-0.0598),-0.0460$ (-0.1116), and -0.0616 (-0.1478), respectively, for 1-, 4-, 8-, and 12-quarters-ahead. Thus, our expected return proxies appear to generate realistic values for multiple points in the future. However, for a more comprehensive assessment of these proxies we turn to the next section.

\subsection{Cross-Sectional Validation Tests}

We validate the model by examining the cross-sectional properties of these expected return proxies and to assess its reliability. In particular, we examine the ability of these firm-level estimates of expected returns to predict the cross section in future holding period returns up to three-years ahead.

We conduct regression-based tests as well as portfolio-based tests. In the first set of tests, we estimate pooled regressions of realized log returns over a holding period horizon on our measure of ex ante expectations of log stock returns over that horizon:

$$
r_{i, t+T}=\delta_{0}+\delta_{1} \mathbb{E}_{t}\left[r_{i, t+T}\right]+w_{i, t+T}
$$

Having true conditional expectations of holding period returns yields $\delta_{0}=0$ and $\delta_{1}=1$ for all holding periods $T$, but in lieu of satisfying these absolute benchmarks, positive and significant $\delta_{1}$ coefficients imply positive return sorting ability on average.

Table 3 reports regression estimates of equation (17) for $T=3-, 12-, 24-$, and 36months. In columns (5)-(8), we include industry fixed effects to test the return pre- 
dictability of our proxies within industry. These results indicate that the model-implied proxies of expected log returns are significantly associated with future log returns up to three years ahead. The coefficients on 3-, 12-, 24-, and 36-month expected log returns are 0.8555 (0.8342), 0.7162 (0.6852), 0.5954 (0.5606), and 0.5244 (0.4904), respectively, for the specifications without (with) industry fixed effects, with each coefficient significantly different from 0 at the $1 \%$ level. ${ }^{13}$ The magnitudes of the slope coefficients attenuate as the holding period lengthens. Since our expected return proxies are conditional on the information set at time $t$, measurement errors are likely to be greater at longer holding period horizons, contributing to greater attenuations of the slope coefficients. Nevertheless, the associations between expected and realized returns remain highly statistically significant at longer horizons.

The one-quarter ahead expected log return proxies perform especially well. The baseline specification of column (1) reports a slope coefficient of 0.8555 , which is not only economically large and statistically significant at the $1 \%$ level, but we also fail to reject the null hypothesis that this slope coefficient is different from 1 at the $10 \%$ level. Furthermore, we also fail to reject the null that the constant is no different from 0 at the $10 \%$ level. In untabulated tests, we find similar, but generally stronger, results using Fama-MacBeth regressions. The coefficients on 3-, 12-, 24-, and 36-month expected log returns are $0.8415,0.7006,0.5947$, and 0.5268 , respectively, with each coefficient being significant at the $1 \%$ level.

These regression results also indicate that the firm-level proxies of expected returns explain $1.2 \%, 2.8 \%, 3.6 \%$, and $4.03 \%$ of the variation in 3-, 12-, 24-, and 36-month ahead returns, respectively, so that most of the variation in firm-level stock returns are driven by news. Moreover, we find that most of the unexpected stock returns are driven by cash

\footnotetext{
${ }^{13}$ We use two-way cluster robust standard errors, clustering by time and by firm, to account for both cross-sectional and time-series correlation in the residuals (see Petersen, 2009 and Gow, Ormazabal, and Taylor, 2010).
} 
flow news, consistent with the findings of Vuolteenaho (2002). ${ }^{14}$

We complement the above parametric return regression tests with a portfolio-level analysis to test the cross-sectional predictive ability of expected holding period return proxies. ${ }^{15}$ We form, on each forecast date, portfolios based on quintile as well as decile rankings of the expected log return proxy, and summarize the average ex post log return produced by each equal-weighted quantile portfolio. We perform this exercise across different horizons, matching quantile portfolios for 3-, 12-, 24-, and 36-month ahead expected log returns to their respective ex post realized log returns.

Table 4 reports the results of the portfolio exercise and provides, consistent with the regression tests of Table 3, further evidence that the model-implied proxies exhibit significant ability to predict the cross section of future returns. In all cases, quintile portfolios sort future log returns monotonically, with economically and statistically significant average spreads between the top and bottom portfolios. We find an average quintile (decile) spread in 3-, 12-, 24-, and 36-month ahead market-adjusted [left-hand side of the table] $\log$ returns of $0.0790(0.1094), 0.2491$ (0.3286), 0.3297 (0.4240), and 0.3481 (0.4483), respectively, with all average log return spreads significantly different from 0 at the $1 \%$ level. To account for the possibility that these equal-weighted portfolio returns could be driven by small firms, we also replicate the portfolio exercise (right-hand side of the table) but summarize size-adjusted log returns, and find qualitatively similar, although

\footnotetext{
${ }^{14}$ Our model also leads to a simple decomposition of unexpected returns, similar to Vuolteenaho (2002). By combining equations (1) and (5), unexpected returns can be expressed as

$$
r_{t+1}-\mu_{t}=A_{1} \xi_{t+1}+A_{2} \epsilon_{t+1}+\nu_{t+1},
$$

for some constants $A_{1}, A_{2}$. Here, $A_{1}^{2} \operatorname{Var}\left[\xi_{t+1}\right]$ represents the variance in expected returns news.

Parameters of this equation can be estimated by regressing $r_{t+1}-\hat{\mu}_{t}$ on $\hat{\xi}_{t+1}=\hat{\mu}_{t+1}-\hat{\kappa} \hat{\mu}_{t}$ and $\hat{\epsilon}_{t+1}=\hat{\mathbb{E}}_{t+1}\left[\right.$ roe $\left._{t+2}\right]-\hat{\omega} \hat{\mathbb{E}}_{t}\left[\right.$ roe $\left._{t+1}\right]$, where $\hat{\mathbb{E}}_{t}\left[r_{t+1}\right]$ is our model-implied expected rates of quarterly returns, $\hat{\mathbb{E}}_{t}\left[\right.$ roe $\left._{t+1}\right]$ is lagged roe, and $\hat{\kappa}$ and $\hat{\omega}$ are the sample average persistence parameters.

This estimation yields $\hat{A}_{1}=-4.8633, \hat{A}_{1}^{2} \times \hat{V}\left[\hat{\xi}_{t+1}\right]=0.02300$, and $\hat{V}\left[r_{t+1}-\hat{\mu}_{t}\right]=0.09137$. Thus, our model suggests that approximately $23.90 \%$ of the variance in unexpected returns is explained by the variance in discount rate news, similar to Vuolteenaho (2002) who estimates this ratio to be approximately $25 \%$ using a VAR.

${ }^{15}$ As Cochrane (2011) noted, these are essentially nonparametric regression tests.
} 
slightly weaker in magnitude, results.

We also find that our proxies sort future net returns (rather than logs). The last two rows of Table 4, Panel A reports average quintile (decile) spreads in 3-, 12-, 24-, and 36month market-adjusted returns of 0.0389 (0.0548), 0.1109 (0.1542), 0.2305 (0.3044), and 0.3551 (0.4632), respectively, again with all average spreads significantly different from 0 at the $1 \%$ level. As before, size-adjusted spreads provide similar results. The spreads in realized net returns provides a clearer picture of the return sorting ability of our expected return proxies. The quarterly quintile (decile) spread implies a compounded annual market-adjusted return of $16.49 \%(23.79 \%)$, and a compounded annual size-adjusted return of $15.15 \%(22.33 \%)$.

In untabulated results, we also conduct the portfolio tests within each industry. That is, we form, on each forecast date and for each industry, portfolios based on quintile as well as decile rankings of the expected log return proxy. Our findings here are very consistent (both quantitatively and qualitatively) with those of Panel A, with average spreads that are similar to, and sometimes even larger than, those of Panel A.

These findings are significant in illustrating how investors can use just two firm fundamentals to construct firm-level proxies of expected returns that sorts future returns. Moreover, the quarterly forecasts of firm-level returns are especially reliable and line up well with the behavior of true expected returns. These findings also demonstrate, consistent with Lewellen (2013), that firm-level expected return proxies obtained from pooled regressions of realized returns on predictors exhibit strong cross-sectional predictive properties. 


\section{Robustness Tests and Supplemental Analyses}

We provide in this section analyses on the sensitivity and robustness of our main results to different implementations of the model as well as compare our model-implied estimates of expected net returns to those implied from standard factor models. We also assess the model's ability to extract time varying conditions in the aggregate.

\subsection{Sensitivity to Training Sample Period}

We first test the performance of our expected quarterly log returns estimates to the choice of the burn-in period, following Kelly and Pruitt (2013). Our primary results splits the sample at 1985Q4, using the data from from 1971Q1 to 1985Q4 as the initial training sample. In these robustness tests we produce the regression-based and portfolio-based returns tests for a series of expected quarterly log returns estimated using varying sample splits for the initial burn-in period, from 1981Q1 to 1999Q4. ${ }^{16}$

The first row of Figure 1 reports the slope coefficients from regression-based tests of Table 3, with the right-hand-side graph representing the specification that includes industry fixed effects, across different sample-split dates. Both of the figures in this row show that across the different burn-in periods considered, the resultant proxies of expected returns produce out-of-sample regression slope coefficients that are fairly stable and economically as well as statistically significant.

Out-of-sample decile portfolio spreads, reported in the second and third rows of Figure 1 , confirm the robustness of our estimation to the choice of initial burn-in period. We replicate the portfolio-based tests of Table 4, specifically the spreads in 3-month ahead realized net returns between the top and bottom decile portfolios, using expected log returns proxies formed using different burn-in periods. The right-hand-side column rep-

\footnotetext{
${ }^{16}$ Similar to Kelly and Pruitt (2013), our earliest cutoff utilizes a training sample of 10 years and our last cutoff leaves an out of sample forecast horizon of approximately 15 years.
} 
resents results using decile portfolios formed within industry. In both the market-adjusted (second row), and the size-adjusted (third row) results, we find that the decile portfolio spreads are consistently economically and statistically significant across all sample splits.

\subsection{Instrumental Variables Estimation}

The next set of tests addresses the potential issue arising from the use of the most recently reported log ROE $\left(\right.$ roe $\left._{i, t}\right)$ to proxy for expected log ROE $\left(h_{i, t}\right)$ over the next period, which likely produces inconsistent estimates of $\beta_{2}$ in an OLS estimation of equation (12). ${ }^{17}$ Our model implies that the lag value of $\log \operatorname{ROE}\left(\right.$ roe $\left._{i, t-1}\right)$ is a valid instrument for roe $_{i, t}$ and can be used to mitigate the potential biases in the estimated coefficients. It is easily shown that the instrument relevance condition is met so long as $\rho \neq 0 ; \rho=0$ implies that expected log ROE as well as realized log ROE are both white noise, with the latter easily rejected empirically. Satisfying the instrument exogeneity condition follows from the time-series structure of the model. Intuitively, the source of the measurement error bias stems from the correlation between $r_{0 e}{ }_{i, t}$ and the expected roe innovations for the period, $\nu_{i, t}$, or expected roe news (with respect to period $t-1$ information). It follows that there is no correlation between $\operatorname{roe}_{i, t-1}$ and $\nu_{i, t}$.

Table 5, Panel A reports the distributional summary statistics for the estimated model parameters using an instrumental variables (IV) regressions approach. ${ }^{18}$ The reporting format follows that of Table 1, Panel A with the exception that the fourth column reports first-stage $F$-statistics from the IV regressions.

Our estimation shows that $r o e_{i, t-1}$ is a relevant instrument for roe $_{i, t}$, with first stage $F$-statistics of 77.18 at the $5^{t h}$ percentile and 1555.04 , on average. The coefficient on roe $_{i, t}$ increases to an average (median) of 0.6038 (0.5303) from the OLS estimates of 0.2695

\footnotetext{
${ }^{17}$ This is clearly seen in the correlation between roe $_{i, t}$ and $\zeta_{i, t+1}$ through $\nu_{i, t}$.

${ }^{18}$ All other aspects of the model estimation, in terms of sample selection, data cleaning, etc., are identical to the OLS estimation procedure.
} 
(0.2323), suggesting that the OLS estimates may have been attenuated by measurement errors; however, the variation in this coefficient nearly tripled to a standard deviation of 0.4148 from the OLS case of 0.1591 . Thus, as expected, there is a trade-off between bias and efficiency between these two sets of estimates. The constant coefficient estimates as well as the estimates of the coefficient on $b m_{i, t}$ increased in variability, relative to their OLS counterparts; however, while the mean (median) attenuated substantially for the constant coefficient, from 0.0074 (0.0091) in the OLS case to 0.0036 (0.0045), it remained relatively unchanged for the $b m_{i, t}$ coefficient, from the OLS estimate of $0.0263(0.0251)$ to $0.0275(0.0269)$.

The increased variability in all estimated coefficients also led to the increased variability in the implied model parameters. However, this is attenuated by our winsorizing the implied persistence parameters at 0.9999. In terms of the mean (median) of the estimated model parameters, the implied long-run unconditional expectation $(\mu)$ decreased to 0.0080 (0.0133) compared to the OLS estimate of 0.0099 (0.0127), whereas the implied persistence parameter for expected $\log \operatorname{ROE}(\omega)$ experienced an increase to 0.9498 (0.9628) from the OLS estimate of 0.9036 (0.9244) and the implied persistence parameter for expected log returns remain relatively unchanged in the mean (median).

Table 5, Panel B reproduces the return tests of Table 3, but using the IV-based proxies of expected log returns. We continue to find significant return predictability, both in the cross-section and within industry, up to three-years ahead. The coefficients on 3-, 12, 24-, and 36-month expected log returns are 0.6102 (0.5866), 0.5006 (0.4742), 0.4056 (0.3791), and 0.3485 (0.3231), respectively, for the specifications without (with) industry fixed effects, with each coefficient significantly different from 0 at the $1 \%$ level. Although they remain highly significant, these coefficients are uniformly lower than the OLS-based estimates. In untabulated tests, we find similar results using Fama-MacBeth regressions. The coefficients on 3-, 12-, 24-, and 36-month expected log returns are 0.6163, 0.5038, 
0.4199 , and 0.3662 , respectively, with each coefficient being significant at the $1 \%$ level. We also replicate in untabulated tests the portfolio sort tests of Table 4 using the IV-based proxies and continue to find return predictability up to the 3-year horizon. Although quintile and decile portfolio hedged returns continue to be significant at the $1 \%$ level and similar to those based on OLS-estimated proxies, they are almost uniformly smaller in magnitude.

Overall, the use of IV estimation to mitigate potential measurement error bias produces similar, but generally noisier, parameter estimates. Our findings that the IV-based estimates under-perform the OLS-based estimates suggest that efficiency loss in the IV estimation process, arising from the first-stage estimation, may outweigh the gains from bias reduction.

\subsection{Annual Accounting Data}

We also examine the sensitivity of our baseline results to the use of quarterly accounting data, which may induce measurement errors in parameter estimates due to potential seasonality in quarterly earnings. As an alternative, we calibrate equation (12) using log annual returns and annual accounting data - that is, we assume that expected log annual returns and expected log annual ROE follow $\mathrm{AR}(1)$ processes.

We make forecasts of expected future 1-, 2-, and 3-year holding period log returns on a annual basis, at the end of June in each calendar year, and, as before, and calibrate the model by estimating equation (12) via pooled ordinary least squares (OLS) regressions, pooling at the Fama and French (1997) 48 industry level and using historical realized log annual returns, log BM ratios, and log ROE. In matching the financial statement data to the forecast date, we assume that annual financial statement data are observable 3 months after the fiscal year end, consistent with our baseline estimation assumptions. For example, to make a forecast at the end of June 2010 we use annual realized log returns 
up to June 30, 2010 and observable annual $b m_{i, t}$ and $r o e_{i, t}$ up to June 30, 2009. We make forecasts at the end of each June 1980 to 2012. As before, we use a burn-in period of 15 years, from 1965 to 1979, to train the model and use a recursive estimation approach. Long-run unconditional mean estimates are winsorized at 1.2 and -1.2. All other aspects of the estimation process are identical to the quarterly OLS-based estimates.

Table 6, Panel A provides the summary statistics for the OLS-based parameter estimates using annual accounting data. Not surprisingly, the persistence parameters estimated from annual data tend to be lower than those implied by the quarterly data, whereas the long-term unconditional expected log returns are, on average, higher. These persistence parameter estimates are consistent with the quarterly-based estimates in the following sense. The mean (median) annual implied persistence parameter for expected log returns of $0.9227(0.9294)$ is close to the annualized mean (median) quarterly value of $0.9834^{4}=0.9352\left(0.9847^{4}=0.9402\right)$. Similarly, the mean (median) annual persistence parameter for expected log ROE of 0.7721 (0.7861) is relatively close to the annualized mean (median) quarterly value of $0.9036^{4}=0.6667\left(0.9244^{4}=0.7302\right)$.

Table 6, Panel B reports regression-based return tests of Table 3 using the annualbased proxies. As with the quarterly proxies, we find strong evidence that our expected log return proxies estimated based on annual financial statement data exhibit strong return predictability both overall and within industry. The coefficients on 12-, 24-, and 36-month expected holding period log returns are 0.5832 (0.5450), 0.5132 (0.4729), and 0.4620 (0.4234), respectively, for the specifications without (with) industry fixed effects, with each coefficient significantly different from 0 at the $1 \%$ level. However, all of these slope coefficients are smaller in magnitude compared to those produced by the quarterlybased estimates. We find very similar results using Fama-MacBeth return regressions.

Also in untabulated results, we produced IV-estimates of expected log returns using annual financial data, using the previous year's log ROE as an instrument for the current 
year's log ROE. The patterns of change, from OLS to IV, in the annual-data-estimated coefficients and implied parameters are similar to those using quarterly data. For example, the IV-estimation generally increases the spreads in the distributions of the estimated coefficients, especially the coefficient on roe $_{i, t}$. Moreover, regression-based tests of these annual-data-based IV-estimated proxies continue to exhibit significant return predictability up to 3-years ahead, with all slope coefficients being significantly different from 0 at the $1 \%$ level; however, as was the case with quarterly data, the magnitudes of the coefficients are uniformly generally lower than their OLS-based counterparts reported in Table 6.

Overall, our model does not appear to be very sensitive to estimation in annual (rather than quarterly) increments in terms of producing proxies of expected returns that exhibit significant firm-level return predictability. Nevertheless, the quarterly-based estimates outperform the annual-based estimates across all holding period horizons in both regression-based tests as well as portfolio sorts.

\subsection{Expected Net Returns and Comparison to Factor Model Estimates}

Our above analyses show that the model produces proxies of expected log returns that exhibit strong cross-sectional properties and are robust to different empirical implementations. In this subsection we extend the above analyses to adapt our log-based model to produce proxies of expected net (or simple) returns. Specifically, we supplement equation (12) with the following equation,

$$
n r_{i, t+1}=A e^{\beta_{0}+\beta_{1} b m_{i, t}+\beta_{2} r o e_{i, t}}-1+\eta_{i, t+1}^{n r},
$$


relating expected net returns $\left(A e^{\beta_{0}+\beta_{1} b m_{i, t}+\beta_{2} \text { roe }_{i, t}}-1\right)$ to expected log returns and realized net returns $\left(n r_{i, t+1}\right)$. The intuition for this functional form for expected net returns follows from log-returns that are conditionally normal. In this case, expected returns are multiplicatively related (through conditional log-return variances) to the exponential of expected log-returns. The $A$ parameter represents this multiplicative relation.

Here, the un-expected returns $\left(\eta_{i, t+1}^{n r}\right)$ are assumed to be mean 0 white noise with finite second moments. The parameters can be estimated using constrained two-equation nonlinear seemingly unrelated regressions (SUR), combining equations (12) and (20) and constraining the coefficients $\left(\beta_{0}, \beta_{1}, \beta_{2}\right)$ to be the same across the two equations. We estimate this system recursively using quarterly data, and all other aspects of the estimation are identical to the baseline results.

Table 7, Panel A reports distributional summary statistics on the estimated coefficients and implied model parameters following the format of Table 1, Panel A. While most parameter estimates are similar to those produced by our baseline results, the coefficients on $r o e_{i, t}$ and the implied persistence parameter of expected ROE are attenuated relative to the baseline results of Table 1. Moreover, on average (at the median), expected gross returns are $3.46 \%$ (3.34\%) higher than expected log returns, translating to proxies of expected quarterly returns that are $2.89 \%$ (2.91\%) at the mean (median) or $12.07 \%$ $(12.16 \%)$ annualized.

Turning to performance assessment, we report in Panel B, Table 7 regression-based tests similar to those of Table 3, but we replace realized log returns with realized net returns and proxies of expected log returns with proxies of expected net returns. These results indicate that the model-implied proxies of expected holding period net returns significantly predict the cross section of future net returns up to three years ahead. ${ }^{19}$ The coefficients on 3-, 12-, 24-, and 36-month expected net returns are 0.5973 (0.5986),

\footnotetext{
${ }^{19}$ For simplicity, we apply the same $A$ coefficient to convert expected log returns at different horizons to expected net returns.
} 
0.4361 (0.4997), 0.4129 (0.4748), and 0.3856 (0.4368), respectively, for the specifications without (with) industry fixed effects. Similar to our baseline results, not only are these coefficients economically significant, but they are also uniformly statistically significant at the $1 \%$ level; also similar to the baseline results is the attenuation in the magnitudes of the slope coefficients as the holding period lengthens.

We also compare these estimates of expected returns to those derived from three standard factor models: CAPM, the Fama and French (1993) three-factor model, and a four-factor model which augments the three-factor model with a momentum factor [the UMD factor obtained from Ken French's data library (Fama and French, 1996)]. At the end of each calendar quarter $t$ we estimate the expected one-quarter ahead returns as

$$
\hat{\mathbb{E}}_{t}\left[n r_{i, t+1}\right]=r f_{t+1}+\sum_{j=1}^{J} \hat{\gamma}_{i} \hat{\mathbb{E}}_{t}\left[f_{j, t}\right]
$$

for each factor model (with $J=1,3,4$ factors), where $\hat{\gamma}_{i}$ are the estimated factor sensitivities, estimated in time-series for each firm using monthly stock and factors' returns over the 60 months prior to the forecast date. Expected quarterly factor returns are estimated based on the trailing average 60-month factor returns multiplied by three. We compound monthly risk-free rates from the Ken French's factor returns data to obtain quarterly risk-free rates.

Table 8, Panel A (B) reports the regression-based (portfolio-sort-based) return tests of Table 3 (4), but replace realized log returns with realized net returns and compare the performance of the model-implied proxies of expected quarterly returns to the factorbased proxies ("CAPM", "FF3", and "FF4" for the one-, three-, and four-factor models, respectively). The analyses are conducted for the subset of firm-year-quarter observations with non-missing values for all four proxies.

We find that the model-implied proxies dramatically outperform the factor-based 
proxies in their cross-sectional predictive ability. Panel A's regression-based tests reveal that the model-implied proxies of expected quarterly returns is the only one with positive and significant slope coefficient: the specification without (with) fixed effects produced a slope coefficient of 0.5620 (0.5577), similar to those reported in Table 7 which uses a larger sample. In fact, the factor-based proxies uniformly produced negative slope coefficients that, with the exception of the CAPM in the specification without fixed effects, are statistically significant at the $10 \%$ level.

These findings are corroborated by the portfolio-sort-based tests of Panel B, which shows the model-implied proxies of expected quarterly returns to be the only one that produces quantile portfolio spreads that are positive and significant. We find that the spread between the top and bottom decile portfolios in average market-adjusted (sizeadjusted) returns is $5.38 \%(4.49 \%)$, translating to annualized returns of $23.32 \%(19.21 \%)$ and similar to those produced by the model-implied proxies of expected log returns, and is statistically significant at the 1\% (1\%) level. In contrast, CAPM-based proxies produced quantile portfolio average market-adjusted and size-adjusted spreads that are negative but are statistically no different from 0 at the $10 \%$ level, whereas the three-factor (four-factor) model based proxies produced spreads that are negative and statistically significant at the $10 \%(1 \%)$ level.

The findings of Table 8 suggest that though CAPM is an elegant theory of firm-level expected rates of returns, its empirical implementation fails to exhibit any meaningful predictive ability for the cross section of future returns. The empirically-motivated multi-factor models, while they appear to explain returns in-sample, also fails to exhibit predictive ability out-of-sample. Our proxy of firm-level expected returns is derived from a simple present value model that is parsimonious, easy to implement, and exhibits significant ability to predict the cross section of future returns. It can therefore be viewed as a simple and practical alternative to the factor-based models for obtaining firm-level 
expected returns.

\subsection{Supplemental Analyses: Aggregate Level Evidence}

Though the main focus of the paper is on the cross-sectional properties of the firm-level estimates of expected returns implied by BM and ROE, in this subsection we investigate how the model performs in capturing the time-series variations in aggregate conditions.

\subsubsection{Expected Returns and the State of the Economy}

We begin by examining whether, for a representative firm, our proxies of expected returns track economic conditions. Following standard economic theory (e.g., Sharpe, 1964; Merton, 1973), we expect conditional risk premiums, and therefore the conditional expected rates of returns, to be elevated during times of uncertainty.

Figure 2 shows, for each quarter in our forecast period (i.e., 1986Q1 until 2013Q3) and for a "representative" firm in our sample, the annualized conditional expected holding period returns over all horizons up to 30-years (the "expected return curve"). We construct this surface following equation (8) using the median estimated parameters, $b m_{i, t}$, and roe $_{i, t}$ available at the end of each quarter. ${ }^{20}$

This surface exhibits several important characteristics about the evolution of expected holding period returns. First, our estimates show that for the median firm, conditional on survival, the expected annualized holding period returns tend to increase with the holding period horizon, producing a positive-sloping expected returns curve for most periods. Second, during of periods of economic distress (e.g., the three recessions from 1990 to 2009), short-horizon expected returns become high relative to long-horizon expected

\footnotetext{
${ }^{20}$ To transform expected log returns into expected returns, we assume that stock returns are conditionally log normal and add one-half the variance of log stock returns to the estimate of expected log returns. We take the median of the firm-level variance in historical log returns, using historical returns data from the same period over which the model parameters and the expected log returns are estimated, over the set of firms with at least 30 quarters of returns data.
} 
returns and the slope of expected returns curve becomes less positive. Third, the difference between long-horizon expected returns are most pronounced times of economic expansion.

To see these patterns more clearly, Figure 3 plots the differences between the longand short-horizon end of the expected returns curve across our sample period. We plot two rate spreads in the top and bottom panels of the figure, respectively: ten-year less three-month ahead spreads in annualized expected returns and thirty-year less threemonth ahead spreads in annualized expected returns. As reference, we also include these spreads in risk-free rates and highlight US economic recessions, as defined by the National Bureau of Economic Research, in red to better identify the behavior of the spreads during economic downturns or times of high uncertainty. ${ }^{21}$

Consistent with the three-dimensional surface, this figure - in particular the bottom panel which plots the spread between the annualized expected thirty-year and threemonth returns - shows that the spread between long- and short-term conditional expected returns on average are positive but less positive during recessionary times. Together, the patterns seen in Figures 2 and 3 are consistent with the economic intuition that when there is a high level of uncertainty or risk in the economy, the cost of financing a new project or issuing new equity in the short-term is high relative to waiting until economic conditions improve. In times of expansion or growth (e.g., the mid-2000's), on the other hand, the spreads between long- and short-term expected returns become more positive, implying that issuing new equity would be relatively cheaper in the short-run and one would rationally expect increased equity issuance during these times.

We note that the generally upward-sloping nature of the conditional expected returns curves in part reflects the modeling assumption that, in the long run, $b m_{i, t}$ is expected to converge to 0 . Since the $b m_{i, t}$ for a representative firm in our sample is negative (i.e.,

\footnotetext{
${ }^{21}$ Risk-free rates taken from the St. Louis Fed's treasury constant maturity rate series. If risk-free rates are missing for a certain maturity, they are interpolated using a cubic spline.
} 
market value of equity is larger than book value of equity), for such a firm, all else equal, the unconditional expected return should be higher than the conditional short-horizon expected return under the model. While we do not believe that the convergence of market with book in steady state is an unrealistic assumption — in fact this is congruent with perfect mark-to-market accounting — we acknowledge that if $b m_{i, t}$ could be expected to converge to a non-zero constant, our estimates of long-run unconditional expected returns could be biased. However, to the extent that such a bias is relatively stable over time for the median firm, we can interpret the changes in the difference between the longhorizon and short-horizon annualized expected returns as tracking changes in economic conditions.

Together, the patterns illustrated in Figures 2 and 3 show that, for the median firm, the dynamics of our model-implied proxies of expected returns track economic conditions in a manner consistent with economic theory.

\subsubsection{Predicting Market-Level Returns}

Our final test investigates the model's ability to generate predictors of aggregate returns. While this is not the main focus of the present paper, we pursue this line of exploratory analysis for two reasons. First, a good model of expected returns should, in principle, produce proxies that can predict future returns both in the cross section and in time series. We are not aware of such a model or forecaster in the existing literature and believe that this is an important subject of research in this area. Second, much of the finance literature has been focused on the time-series variation in market-level returns, both explaining them in-sample as well as predicting them out-of-sample (see, e.g., Welch and Goyal, 2008; Campbell and Thompson, 2008). In particular, there is a growing literature focusing on exploiting present value relations to identify expectations for aggregate returns, whereas we exploit present value relations to identify firm-level 
expected returns.

To assess our model's ability to generate predictors of aggregate returns, we estimate equation (12) using future market log returns (equal-weighted CRSP index) and the cross-sectional average $b m$ and roe. Following our approach in estimating firm-level expected returns, we make recursive out-of-sample forecasts on a quarterly basis by applying historically estimated coefficients, using all historical data and starting in 1986Q1, to the average $b m$ and roe observed at the end of each calendar quarter. Given the limited number of observations in this time series (i.e., 112 data points, with forecasts from 1986Q1 to 2013Q3), we use robust linear regressions to mitigate the influence of outliers.

We assess the performance of this simple forecasters in the context of existing alternatives in the literature. Most relevant is the recent state-of-the-art forecaster proposed by Kelly and Pruitt (2013) [henceforth "K\&P (2013)"], who filter for expectations of aggregate returns using the cross section of $b m$ ratios. Not only does their model perform well in-sample, but their forecaster performs remarkably well out-of-sample, unlike many previously studied predictors that perform well only in-sample (Welch and Goyal, 2008). For example, filtering from the $b m$ ratios of the 100 size and value-sorted portfolios of U.S. stocks from Fama and French (1993), K\&P (2013) report predictability of monthly (annual) returns that is significant at the 5\% (1\%) level and an out-of-sample predictive $R^{2}$ of $1.1 \%(8.28 \%)$. Thus, for comparison, we adapt their methodology to predict quarterly aggregate returns, using the 100 size and value-sorted portfolios. ${ }^{22}$

Following prior literature and K\&P (2013), we conduct out-of-sample inference with the "encompassing" forecast test, using the ENC-NEW test statistic proposed by Clark and McCracken (2001). This test statistic is commonly used in the forecasting literature to test the null that two predictors provide the same out-of-sample forecasting

\footnotetext{
${ }^{22}$ Following their paper, in constructing the predictor we use a training sample spanning 1930 to 1980 and perform recursive out-of-sample forecasts, which are made again at the end of every calendar quarter for consistency.
} 
performance; in particular, it is used to test one forecaster against a naive predictor: the historical mean of the target series. Panel A, Table 9 reports the test statistics' significance levels obtained from Clark and McCracken (2000), where the critical values for the $0.01,0.05$, and 0.10 levels are provided. The notation " $<x$ " indicates the smallest significance level for which the ENC-NEW statistic exceeds the critical value. We also report the forecast fit by computing the out-of-sample predictive $R^{2}$, defined as $R_{o s}^{2}=1-\frac{\sum_{t=1}^{T}\left(r_{t}-\hat{r}_{t}\right)^{2}}{\sum_{t=1}^{T}\left(r_{t}-\bar{r}_{t}\right)^{2}}$ for each forecaster $\left\{\hat{r}_{t}\right\}_{1}^{T}$ and $\bar{r}_{\tau}$ is the historical average estimated through $\tau-1$.

We find that our simple aggregate predictor exhibits modest ability to predict aggregate returns: with an ENC-NEW statistic, it is significant at the $1 \%$ level and an $R_{\text {os }}^{2}$ of $0.62 \%$. Given its simplicity, we were surprised by this modest performance. In comparison the K\&P (2013) forecaster performs quite well in predicting aggregate returns, producing an ENC-NEW statistic that is significant at the $1 \%$ level and an $R_{o s}^{2}$ of $4.78 \%$. This performance is very consistent with those documented in their paper.

The relatively better performance of the K\&P (2013) forecaster is perhaps not surprising, and could stem from two sources. First, this forecaster is the outcome of a more sophisticated filtering technology. Second, the implementation of this forecaster uses substantially greater data than we do. Whereas their approach uses annual financials going back to 1930s, ours uses quarterly financial statements which are only available since the end of $1970 .^{23}$

To assess the impact of having more limited data on the relative performance of these alternative forecasters, we test the performance of a version of the K\&P (2013) predictor that is estimated using the same training sample period as our predictor, spanning 1971Q1 to 1985Q4. Our results, reported in column (3) of Panel A suggest that the limited data

\footnotetext{
${ }^{23} \mathrm{~K} \& \mathrm{P}$ (2013) approach uses mixed frequencies, combining annual data on book values with monthly data on market values, whereas we match the frequencies of accounting data and market values. In other words, we observe and measure $b m$ and roe with the same frequency as updates of financials, which better maps to the dynamics of our model.
} 
substantially impacts K\&P (2013) forecaster's predictive ability. While the ENC-NEW statistic continues to be significant at the $5 \%$ level, the $R_{o s}^{2}$ is substantially reduced and slightly smaller than those we produce.

We also produce return regression results in Panel B, and find qualitatively similar evidence. The slope coefficient is economically and statistically more significant (1.3518 and significant at the $5 \%$ level) and the $R^{2}$ larger (5.2\%) for the K\&P (2013) forecaster using full data than those produced by our model: a slope coefficient of 0.4936 , statistically significant at the $10 \%$ level, and an $R^{2}$ of $3.2 \%$. However, the variant of the K\&P (2013) forecaster of quarterly data trained on post-1970 data exhibits performance that is more similar to our simple forecaster: it produces a slope coefficient of 0.4512 , statistically insignificant at the $10 \%$ level, and an $R^{2}$ of $1.3 \%$.

In summary, we find that this model produces a forecaster with modest predictive ability of aggregate returns, which is surprising given the limited data and lends support to the model overall. The analysis above also suggests that, as more quarterly financial statements become available, the performance of this simple aggregate predictor could be expected to improve. Together, these results lead to a sanguine assessment of the model. Not only does it produce proxies that exhibit strong cross-sectional properties, but we also document some modest ability to extract information in the time series as well. To our knowledge there does not exist alternative models of expected returns that performs well on both of these dimensions.

\section{Conclusion}

Expected holding period returns are critical in guiding capital allocation decisions. When firm-level expected returns are time-varying - in particular when they revert to different means and with differential speed - the rank ordering of expected holding period 
returns can differ significantly across different horizons. Naive estimates of expected holding period returns can therefore lead investors to significantly misallocate capital.

We provide a novel and relatively simple methodology to obtain expected holding period returns over arbitrary horizons, and document that our proxies predict the crosssection of future returns up to three years into the future. We also document that the model-implied proxies track economic conditions in the aggregate and exhibit modest ability to predict aggregate returns. This is a first model exhibiting predictive ability in both the cross section and in time series.

Our work contributes to empirical studies devoted to developing the estimation and understanding the behavior of expected returns, and provides a practical tool that can be used to analyze investment choices of different horizons. We believe the in-depth exploration of the significance of time-varying expected returns to be an important endeavor for future research in investments and valuation. Future work in this area might adapt this paper's model to incorporate analysts' or other earnings forecasts to improve the quality and accuracy of the model's expected return measures. 


\section{References}

Ang, A. and G. Bekaert (2007). Stock return predictability: Is it there? Review of Financial Studies 20(3), 651-707.

Ang, A. and J. Liu (2004). How to discount cashflows with time-varying expected returns. Journal of Finance 59(6), 2745-2783.

Beaver, W., M. McNichols, and R. Price (2007). Delisting returns and their effect on accounting-based market anomalies. Journal of Accounting and Economics 43(2), 341368.

Callen, J. (2009). Shocks to shocks: A theoretical foundation for the information content of earnings. Contemporary Accounting Research 26(1), 135-166.

Callen, J., O. Hope, and D. Segal (2005). Domestic and foreign earnings, stock return variability, and the impact of investor sophistication. Journal of Accounting Research $43(3), 377-412$.

Callen, J. and D. Segal (2004). Do accruals drive firm-level stock returns? A variance decomposition analysis. Journal of Accounting Research 42(3), 527-560.

Callen, J. and D. Segal (2010). A variance decomposition primer for accounting research. Journal of Accounting, Auditing \& Finance 25(1), 121-142.

Callen, J. L. and M. R. Lyle (2011). The term structure of implied costs of equity capital. University of Toronto Working Paper.

Campbell, J. (1991). A variance decomposition for stock returns. The Economic Journal 101(405), 157-179.

Campbell, J. Y. and S. B. Thompson (2008). Predicting excess stock returns out of sample: Can anything beat the historical average? Review of Financial Studies 21(4), $1509-1531$.

Cheng, Q. (2005). What determines residual income? The Accounting Review 80(1), 85-112.

Clark, T. E. and M. W. McCracken (2000). Not-for-publication appendix to "tests of equal forecast accuracy and encompassing for nested models".

Clark, T. E. and M. W. McCracken (2001). Tests of equal forecast accuracy and encompassing for nested models. Journal of econometrics 105(1), 85-110.

Claus, J. and J. Thomas (2001). Equity premia as low as three percent? evidence from analysts' earnings forecasts from domestic and international stock markets. Journal of Finance 56(5), 1629 - 1666. 
Cochrane, J. (2001). Asset pricing, Volume 14. Princeton University Press, Princeton, NJ.

Cochrane, J. (2011). Presidential address: Discount rates. Journal of Finance 66(4), 1047-1108.

Cochrane, J. H. (2008). The dog that did not bark: A defense of return predictability. Review of Financial Studies 21(4), 1533-1575.

Dichev, I. and V. Tang (2009). Earnings volatility and earnings predictability. Journal of Accounting and Economics 47(1-2), 160-181.

Duffie, D. (2001). Dynamic asset pricing theory. Princeton University Press, Princeton, NJ.

Easton, P. and S. Monahan (2005). An evaluation of accounting-based measures of expected returns. The Accounting Review 80, 501.

Easton, P., G. Taylor, P. Shroff, and T. Sougiannis (2002). Using forecasts of earnings to simultaneously estimate growth and the rate of return on equity investment. Journal of Accounting Research 40(3), 657-676.

Easton, P. D. (2004). Pe ratios, peg ratios, and estimating the implied expected rate of return on equity capital. The Accounting Review 79, 73 - 96.

Fama, E. and K. French (1997). Industry costs of equity. Journal of Financial Economics 43(2), 153-193.

Fama, E. F. and K. R. French (1993). Common risk factors in the returns on stocks and bonds. Journal of financial economics 33(1), 3-56.

Fama, E. F. and K. R. French (1996). Multifactor explanations of asset pricing anomalies. The Journal of Finance 51(1), 55-84.

Feltham, G. A. and J. A. Ohlson (1995). Valuation and clean surplus accounting for operating and financial activities. Contemporary Accounting Research 11(2), 689-731.

Feltham, G. A. and J. A. Ohlson (1996). Uncertainty resolution and the theory of depreciation measurement. Journal of Accounting Research 34(2), 209-234.

Ferreira, M. and P. S. Clara (2011). Forecasting stock market returns: The sum of the parts is more than the whole. Journal of Financial Economics 100(3), 514-537.

Freeman, R., J. Ohlson, and S. Penman (1982). Book rate-of-return and prediction of earnings changes: An empirical investigation. Journal of Accounting Research 20(2), 639-653. 
Gebhardt, W. R., C. M. C. Lee, and B. Swaminathan (2001). Toward an implied cost of capital. Journal of Accounting Research 39(1), 135-176.

Gode, D. and P. Mohanram (2003). Inferring the cost of capital using the ohlson-juettner model. Review of Accounting Studies 8(4), 399-431.

Gow, I. D., G. Ormazabal, and D. J. Taylor (2010). Correcting for cross-sectional and time-series dependence in accounting research. The Accounting Review 85(2), 483-512.

Hayashi, F. (2000). Econometrics. Princeton University Press, Princeton, NJ 1.

Hou, K., M. A. Van Dijk, and Y. Zhang (2012). The implied cost of capital: A new approach. Journal of Accounting and Economics 53, 504-526.

Hughes, J., J. Liu, and J. Liu (2009). On the relation between expected returns and implied cost of capital. Review of Accounting Studies 14, 246-259.

Kelly, B. and S. Pruitt (2013). Market expectations in the cross-section of present values. The Journal of Finance 68(5), 1721-1756.

Lee, C., J. Myers, and B. Swaminathan (1999). What is the intrinsic value of the Dow? Journal of Finance 54 (5), 1693-1741.

Lee, C., E. So, and C. C. Wang (2012). Evaluating implied cost of capital estimates. Stanford University Working Paper.

Lettau, M. and S. C. Ludvigson (2005). Expected returns and expected dividend growth. Journal of Financial Economics 76(3), 583-626.

Lettau, M. and S. Van Nieuwerburgh (2008). Reconciling the return predictability evidence. Review of Financial Studies 21(4), 1607-1652.

Lettau, M. and J. Wachter (2007). Why is long-horizon equity less risky? a durationbased explanation of the value premium. Journal of Finance 62(1), 55-92.

Lewellen, J. (2013). The cross section of expected stock returns. Dartmouth College Working Paper.

Lyle, M. R., J. L. Callen, and R. J. Elliott (2013). Dynamic risk, accounting-based valuation and firm fundamentals. Review of Accounting Studies 18(4), 899-929.

Merton, R. C. (1973). An intertemporal capital asset pricing model. Econometrica: Journal of the Econometric Society, 867-887.

Mohanram, P. and D. Gode (2012). Improving the relationship between implied cost of capital and realized returns by removing predictable analyst forecast errors. University of Toronto Working Paper. 
Nekrasov, A. and M. Ogneva (2011). Using earnings forecasts to simultaneously estimate firm-specific cost of equity and long-term growth. Review of Accounting Studies 16(3), 414-457.

Ohlson, J. (1995). Earnings, book values, and dividends in equity valuation. Contemporary Accounting Research 11(2), 661-687.

Pástor, L., M. Sinha, and B. Swaminathan (2008). Estimating the intertemporal riskreturn tradeoff using the implied cost of capital. Journal of Finance 63(6), 2859-2897.

Pástor, L. and R. Stambaugh (2012). Are stocks really less volatile in the long run? Journal of Finance 67(2), 431-478.

Penman, S. H. and X.-J. Zhang (2002). Accounting conservatism, the quality of earnings, and stock returns. The Accounting Review 77(2), 237-264.

Petersen, M. (2009). Estimating standard errors in finance panel data sets: Comparing approaches. Review of Financial Studies 22(1), 435-480.

Sharpe, W. F. (1964). Capital asset prices: A theory of market equilibrium under conditions of risk. The Journal of Finance 19(3), 425-442.

van Binsbergen, J., M. Brandt, and R. Koijen (2012). On the timing and pricing of dividends. American Economic Review 102(4), 1596-1618.

van Binsbergen, J., W. Hueskes, R. Koijen, and E. Vrugt (2013). Equity yields. Journal of Financial Economics 110(3), 503 - 519.

van Binsbergen, J. and R. Koijen (2010). Predictive regressions: A present-value approach. Journal of Finance 65(4), 1439-1471.

Vuolteenaho, T. (2002). What drives firm-level stock returns? Journal of Finance 57(1), $233-264$.

Wang, C. C. (2013). Measurement errors of expected return proxies and the implied cost of capital. Working Paper.

Welch, I. and A. Goyal (2008). A comprehensive look at the empirical performance of equity premium prediction. Review of Financial Studies 21(4), 1455-1508.

Zhang, X. J. (2000). Conservative accounting and equity valuation. Journal of Accounting and Economics 29(1), 125-149. 


\section{Appendix}

\section{A Log-Linearization}

We begin with the definitions of gross realized returns and ROE, where the latter relies on the clean surplus relation (i.e., $B_{i, t+1}=B_{i, t}+E_{i, t+1}-D_{i, t+1}$ ):

$$
\begin{aligned}
R_{i, t+1} & =\frac{S_{i, t+1}+D_{i, t+1}}{S_{i, t}}, \\
R O E_{i, t+1} & =\frac{B_{i, t+1}+D_{i, t+1}}{B_{i, t}}
\end{aligned}
$$

where $B_{i, t}$ and $S_{i, t}$ are the book value and market value per share of equity at the end of period $t$, respectively, and $D_{i, t+1}$ and $E_{i, t+1}$ are the dividends and net income per share of equity paid or earned from the end of period $t$ to the end of period $t+1$.

(A.1) and (A.2) lead to the following definition for the book-to-market ratio for firm $i$

$$
\frac{B_{i, t}}{S_{i, t}}=\frac{R O E_{i, t+1}^{-1}\left(B_{i, t+1}+D_{i, t+1}\right)}{R_{i, t+1}^{-1}\left(S_{i, t+1}+D_{i, t+1}\right)} .
$$

Taking logs on both sides of (A.3), the log book-to-market ratio $\left(b m_{i, t}\right)$ can be written as

$$
b m_{i t}=r_{i, t+1}-r_{i, t+1}+\ln \left(B_{i, t+1}+D_{i, t+1}\right)-\ln \left(S_{i, t+1}+D_{i, t+1}\right)
$$

where $r_{i, t+1}=\ln \left(R_{i, t+1}\right)$ and roe $_{i, t+1}=\ln \left(R O E_{i, t+1}\right)$.

Following Vuolteenaho (2002) (see also Callen and Segal, 2004; Easton and Monahan, 2005; Callen, 2009), we use a Taylor expansion around a combination of average log dividend-to-book and log dividend-to-price to relate the $b m_{i, t}$ as a linear function of $b m_{i, t+1}, r_{i, t+1}$, and $r o e_{i, t+1}$. 
Adding and subtracting $b m_{i, t+1}$ to (A.4), we obtain

$$
b m_{i, t}=b m_{i, t+1}+r_{i, t+1}-r o e_{i, t+1}+\ln \left(1+e^{d_{i, t+1}-b_{i, t+1}}\right)-\ln \left(1+e^{d_{i, t+1}-s_{i, t+1}}\right)
$$

where $d_{i, t+1}, b_{i, t+1}$, and $s_{i, t+1}$ are log dividends, book value per share, and price per share, respectively.

First order Taylor expansion of the log functions around some point $y$ that is a convex combination of the average log dividend-to-book and log dividend-to-price ratios yields:

$$
\begin{aligned}
\ln \left(1+e^{d_{i t+1}-b_{i t+1}}\right) & \approx \ln (y)+\frac{e^{y}}{1-e^{y}}\left(d_{i t+1}-b_{i t+1}-y\right), \text { and } \\
\ln \left(1+e^{d_{i t+1}-s_{i t+1}}\right) & \approx \ln (y)+\frac{e^{y}}{1-e^{y}}\left(d_{i t+1}-s_{i t+1}-y\right),
\end{aligned}
$$

simplifying (A.5) to:

$$
b m_{i t}=\underbrace{\left(\frac{1}{1-e^{y}}\right)}_{k_{1}} b m_{i t+1}+r_{i t+1}-\operatorname{roe}_{i t+1} .
$$

Solving for log returns yields:

$$
r_{i, t+1}=b m_{i, t}-k_{1} b m_{i, t+1}+r o e_{i, t+1} .
$$

It is also convenient to express this equation as a sum of future values; iterating forward results in:

$$
b m_{i, t}=k_{1}^{T} b m_{i, t+T}+\sum_{j=1}^{T} k_{1}^{j-1}\left(r_{i, t+j}-\operatorname{roe}_{i, t+j}\right) .
$$

Taking conditional expectations and letting $T \rightarrow \infty$ gives:

$$
b m_{i, t}=\sum_{j=1}^{\infty} k_{1}^{j-1}\left\{\mathbb{E}_{t}\left(r_{i, t+j}\right)-\mathbb{E}_{t}\left(\text { roe }_{i, t+j}\right)\right\} .
$$




\section{B Stock Prices}

To derive the stock price equation (6), conditional expectations for some time $t+j$ of $\log \mathrm{ROE}$ and $\log$ returns are required. Letting $h_{i, t} \equiv \mathbb{E}_{t}\left(\right.$ roe $\left._{i, t+1}\right)$ and $\mu_{i, t} \equiv \mathbb{E}_{t}\left(r_{i, t+1}\right)$ follow $\operatorname{AR}(1)$ processes with persistence parameters $\omega_{i}$ and $\kappa_{i}$, respectively, and mean $\mu_{i, t}$, the conditional expectations for some time $t+j$ for $\log \mathrm{ROE}$ and log returns are:

$$
\begin{aligned}
\mathbb{E}_{t}\left(\text { roe }_{i, t+i}\right) & =\mu_{i}+\omega_{i}^{j-1}\left(h_{i, t}-\mu_{i}\right), \text { and } \\
\mathbb{E}_{t}\left(r_{i, t+j}\right) & =\mu_{i}+\kappa_{i}^{j-1}\left(\mu_{i, t}-\mu_{i}\right) .
\end{aligned}
$$

Applying (A.9) and (A.10) to (A.8) yields equation (6).

$$
\begin{aligned}
b m_{i, t} & =\sum_{j=1}^{\infty} k_{1}^{j-1}\left(\mu_{i}+\kappa_{i}^{j-1}\left(\mu_{i, t}-\mu_{i}\right)-\mu_{i}-\omega^{j-1}\left(h_{t, i}-\mu_{i}\right)\right) \\
& =\frac{1}{1-\kappa_{i} k_{1}}\left(\mu_{i, t}-\mu_{i}\right)-\frac{1}{1-\omega_{i} k_{1}}\left(h_{t, i}-\mu_{i}\right) .
\end{aligned}
$$

\section{Expected Return Curves}

Define the expected return from time $t$ to time $t+T$ as:

$$
\mathbb{E}_{t}\left(\sum_{j=1}^{T} r_{i, t+i}\right)=\mathbb{E}_{t}\left(\sum_{j=1}^{T} \mu_{i, t+j-1}\right)
$$

where $\mu_{i, t+j-1}=\mu_{i}+\kappa_{i}^{j-1}\left(\mu_{i, t}-\mu_{i}\right)$.

Then, the cumulative expected returns are given by:

$$
\mathbb{E}_{t}\left(\sum_{j=1}^{T} r_{i, t+i}\right)=\mu_{i} T+\left(\mu_{i, t}-\mu_{i}\right) \sum_{j=1}^{T} \kappa_{i}^{j-1}=\mu_{i} T+\left(\mu_{i, t}-\mu_{i}\right) \frac{\kappa_{i}^{T}-1}{\kappa_{i}-1}
$$



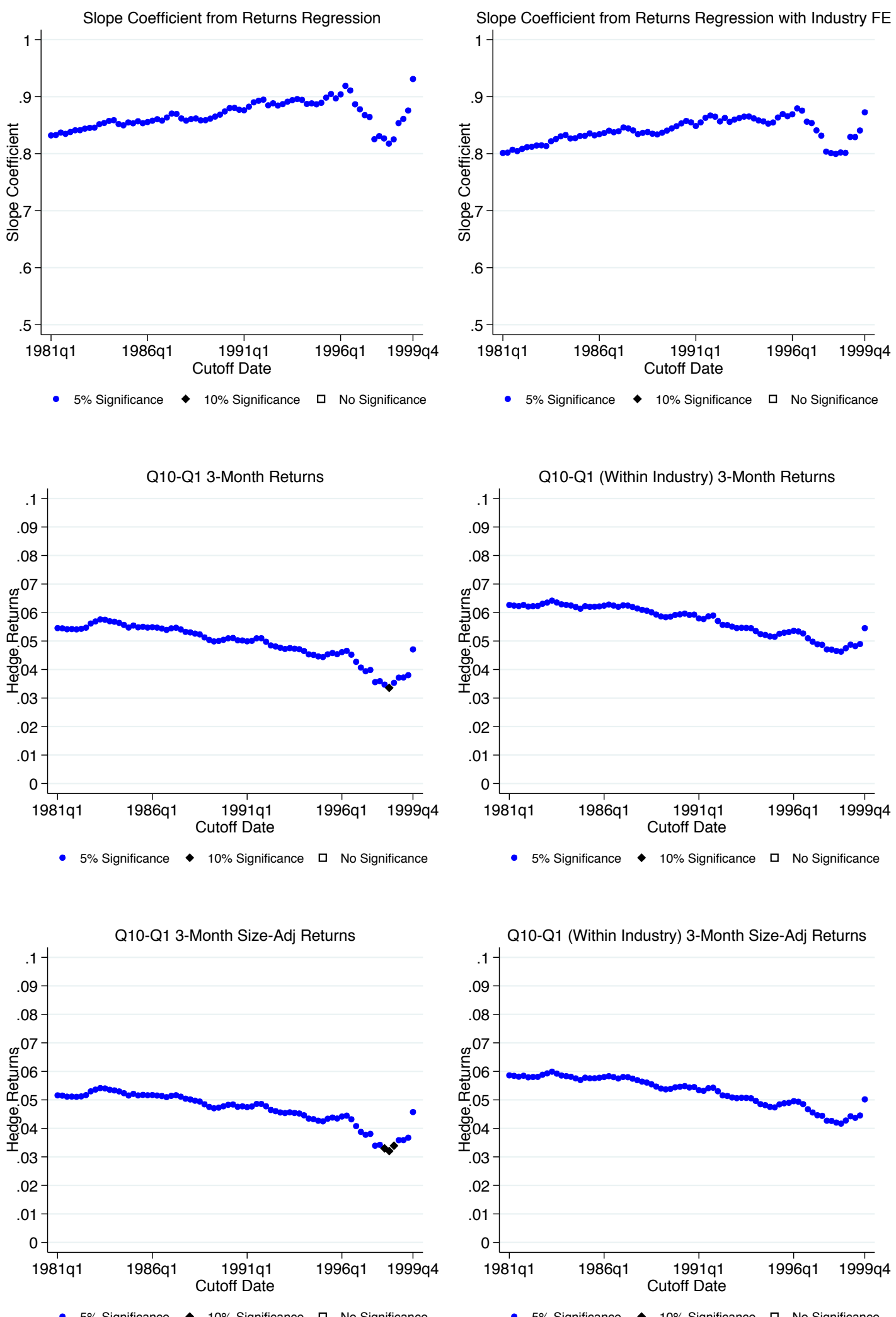

Fig. 1. Out-of-Sample Tests across Sample Split Dates.

Figure 1 plots robustness tests of main results by varying the initial burn-in period of our expected return proxy estimation. We vary the cut-off for the initial training sample from 1981Q1 to 1999Q4, and report results from out-of-sample tests. The first row reports regressionbased tests of Table 3; the second and third rows report decile portfolio spreads of Table 4, and include results from within-industry decile portfolios in the right-hand-side column. 


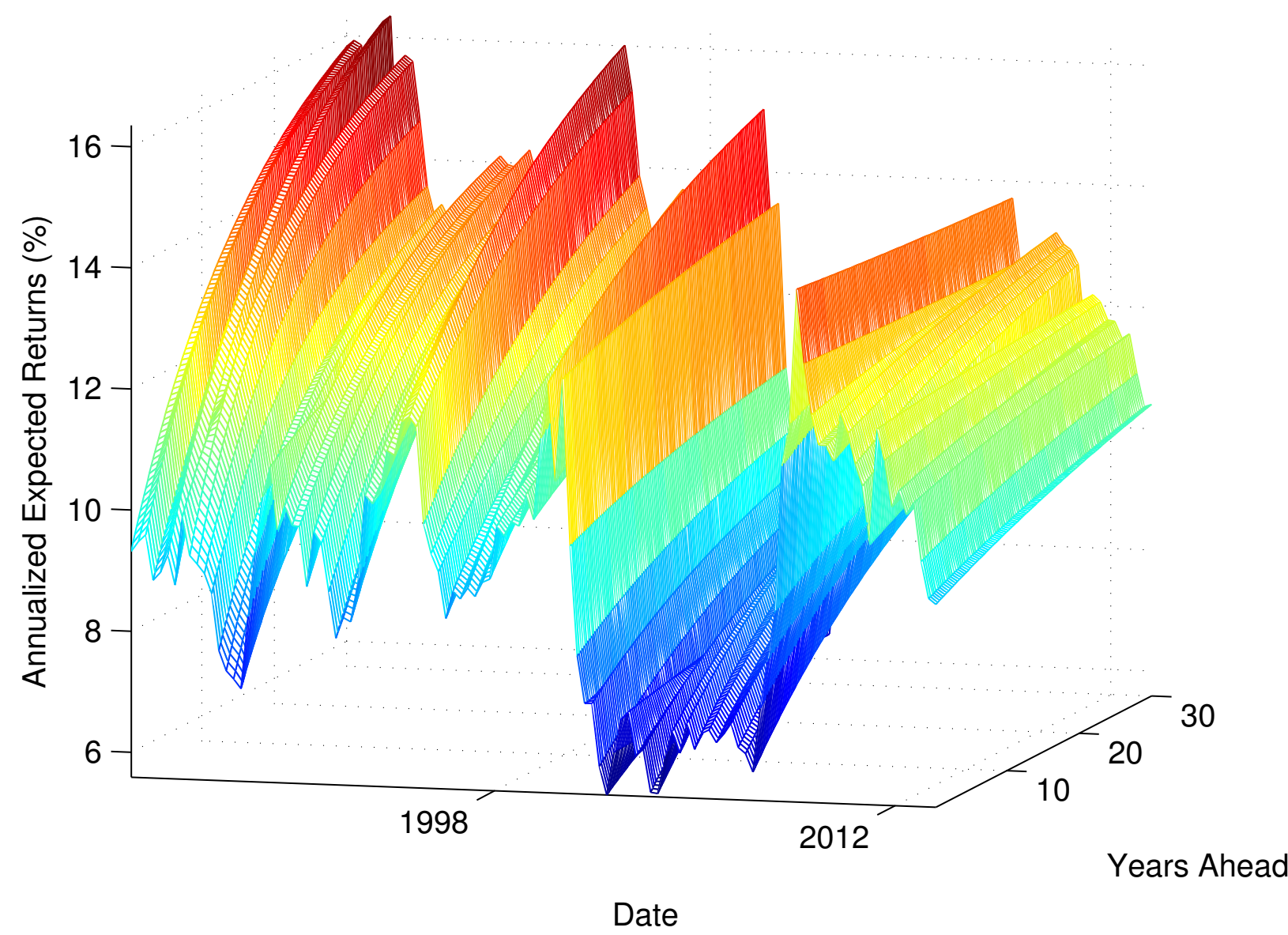

Fig. 2. Expected Return Curves

Figure 2 plots annualized expected returns estimated using equation (9) plus 0.5 times the historical stock return variance. The estimated expected returns are based on sample median estimated parameter values, estimated using historical data, and median log BM ratio and log ROE in each quarter. 
Ten Year Less Three Month Spread

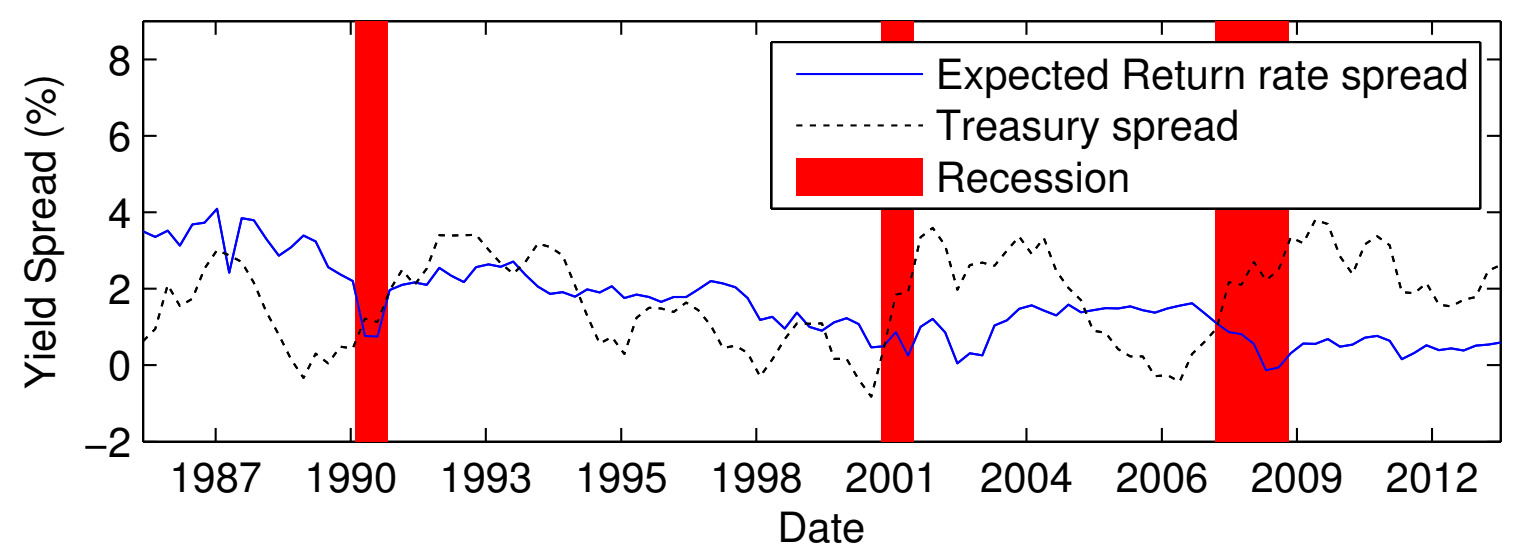

Thirty Year Less Three Month Spread

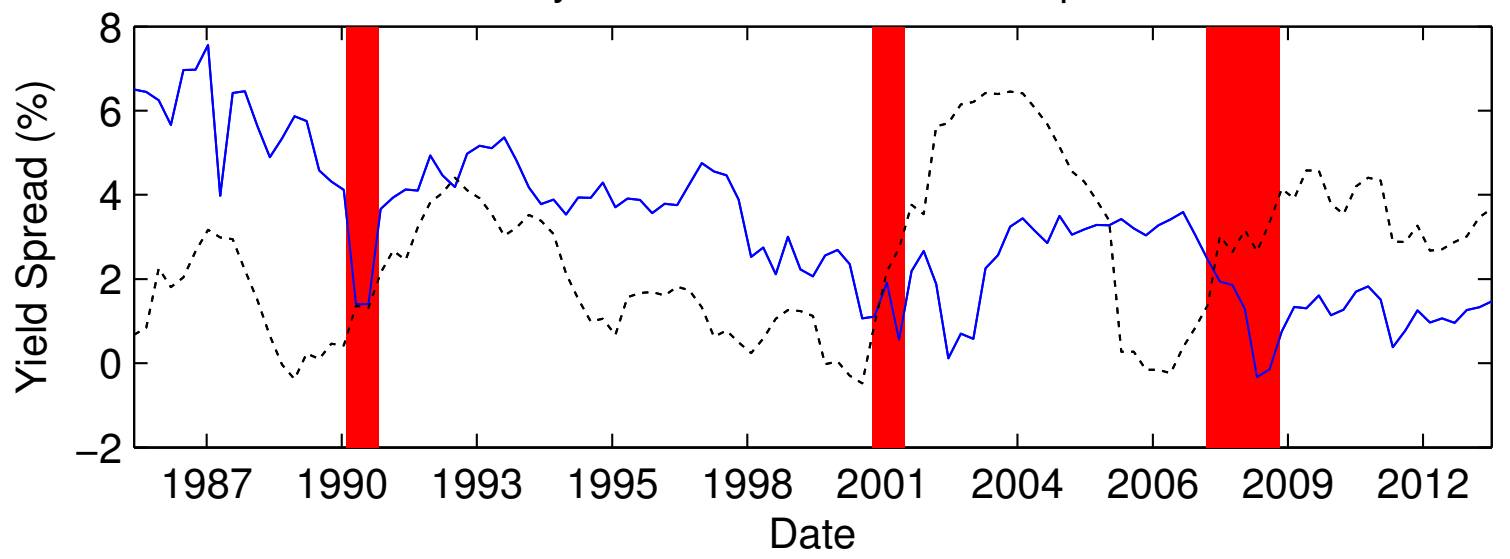

Fig. 3. Expected Rate of Return and Risk-Free Rate Spreads

Figure 3 plots annualized expected returns estimated using equation (9) plus 0.5 times the historical stock return variance along with US treasury rates downloaded from the US Federal Reserve. The estimated expected returns are based on sample median estimated parameter values, estimated using historical data, and median log BM ratio and log ROE in each quarter. 


\section{Table 1. Summary Statistics of Model Parameters}

Table 1 reports summary statistics for the estimated coefficients on $b m_{t}$ and roe $e_{t}$ of equation (12) as well as the implied parameters of the model. The coefficients are estimated by pooled OLS within industry and on a quarterly basis - at the end of March, June, September, and December each year - using the most recent publicly available financial data on book values and earnings to avoid look-ahead bias. The estimation pools all firms within the same Fama and French (1997) 48 industry classification across time, with a burn-in of 60 quarters of data for a given industry. $\kappa$ and $\omega$ represent the quarterly persistence estimates for expected log return on market value and book value of equity, respectively, where the persistence parameters are winsorized at 0.9999. $\mu$ is the long-run expected return on the market value of equity. Panel A reports the distributional summary statistics for the estimated coefficients across industries and time, Panel B the time-series median estimated coefficients and implied model parameters for each industry.

Panel A: Overall Parameter Estimates

\begin{tabular}{lcccccccc}
\hline & \multicolumn{3}{c}{ Regression Coefficients } & & \multicolumn{3}{c}{ Implied Parameters } \\
Statistic & Cons & $b m$ & roe & & $\kappa$ & $\omega$ & $\mu$ \\
\cline { 2 - 4 } \cline { 7 - 8 } P5 & -0.0177 & 0.0126 & 0.1101 & & 0.9674 & 0.7811 & -0.0270 \\
P25 & -0.0009 & 0.0196 & 0.1908 & & 0.9776 & 0.8955 & -0.0002 \\
Mean & 0.0074 & 0.0263 & 0.2695 & & 0.9834 & 0.9036 & 0.0099 \\
Median & 0.0091 & 0.0251 & 0.2323 & & 0.9847 & 0.9244 & 0.0127 \\
P75 & 0.0173 & 0.0322 & 0.3240 & & 0.9903 & 0.9391 & 0.0257 \\
P95 & 0.0280 & 0.0423 & 0.4072 & & 0.9973 & 0.9584 & 0.0356 \\
Std & 0.0141 & 0.0098 & 0.1591 & & 0.0096 & 0.0616 & 0.0189 \\
\hline
\end{tabular}

Panel B: Industry Specific Coefficients

\begin{tabular}{lcccccccc}
\hline & \multicolumn{3}{c}{ Regression Coefficients } & & \multicolumn{3}{c}{ Implied Parameters } \\
Industry & Cons & $b m$ & roe & & $\kappa$ & $\omega$ & $\mu$ \\
\cline { 2 - 4 } \cline { 6 - 7 } Aero & 0.0180 & 0.0328 & 0.2819 & & 0.9770 & 0.9032 & 0.0257 \\
Agric & 0.0000 & 0.0181 & 0.1898 & & 0.9919 & 0.9240 & 0.0000 \\
Autos & 0.0052 & 0.0388 & 0.3674 & & 0.9709 & 0.9282 & 0.0085 \\
Banks & -0.0049 & 0.0246 & 1.1294 & & 0.9852 & 0.9873 & 0.0174 \\
Beer & 0.0194 & 0.0256 & 0.3238 & & 0.9842 & 0.9375 & 0.0297 \\
BldMt & 0.0039 & 0.0274 & 0.3594 & & 0.9825 & 0.9411 & 0.0061 \\
Books & 0.0234 & 0.0157 & 0.1623 & & 0.9942 & 0.9170 & 0.0270 \\
Boxes & 0.0037 & 0.0164 & 0.2599 & & 0.9936 & 0.9577 & 0.0067 \\
BusSv & 0.0138 & 0.0260 & 0.2025 & & 0.9839 & 0.8927 & 0.0163 \\
Chems & 0.0247 & 0.0286 & 0.1565 & & 0.9812 & 0.8599 & 0.0286 \\
Chips & 0.0170 & 0.0376 & 0.1594 & & 0.9721 & 0.8135 & 0.0203 \\
Clths & -0.0078 & 0.0278 & 0.2958 & & 0.9820 & 0.9247 & -0.0112 \\
Cnstr & -0.0178 & 0.0187 & 0.4029 & & 0.9912 & 0.9587 & -0.0296 \\
\hline
\end{tabular}


Table 1. Summary Statistics of Model Parameters

Panel B: Industry Specific Coefficients [Continued]

\begin{tabular}{|c|c|c|c|c|c|c|}
\hline \multirow[b]{2}{*}{ Industry } & \multicolumn{3}{|c|}{ Regression Coefficients } & \multicolumn{3}{|c|}{ Implied Parameters } \\
\hline & Cons & $b m$ & roe & $\kappa$ & $\omega$ & $\mu$ \\
\hline Coal & 0.0208 & 0.0236 & 0.2906 & 0.9863 & 0.9337 & 0.0311 \\
\hline Comps & 0.0044 & 0.0308 & 0.1388 & 0.9789 & 0.8241 & 0.0051 \\
\hline Drugs & 0.0282 & 0.0232 & 0.0498 & 0.9867 & 0.6931 & 0.0301 \\
\hline ElcEq & 0.0133 & 0.0243 & 0.1965 & 0.9856 & 0.8964 & 0.0186 \\
\hline Enrgy & 0.0028 & 0.0240 & 0.2206 & 0.9859 & 0.9067 & 0.0036 \\
\hline FabPr & -0.0002 & 0.0381 & 0.4083 & 0.9716 & 0.9164 & -0.0004 \\
\hline Fin & 0.0103 & 0.0123 & 0.1297 & 0.9976 & 0.9226 & 0.0117 \\
\hline Food & 0.0167 & 0.0260 & 0.3496 & 0.9839 & 0.9384 & 0.0256 \\
\hline Fun & -0.0075 & 0.0216 & 0.2537 & 0.9883 & 0.9250 & -0.0102 \\
\hline Gold & -0.0262 & 0.0031 & 0.0934 & 0.9999 & 0.9815 & -0.0289 \\
\hline Guns & 0.0136 & 0.0185 & 0.2257 & 0.9914 & 0.9293 & 0.0180 \\
\hline Hlth & 0.0036 & 0.0240 & 0.2137 & 0.9859 & 0.9151 & 0.0045 \\
\hline Hshld & 0.0034 & 0.0230 & 0.2784 & 0.9869 & 0.9315 & 0.0046 \\
\hline Insur & 0.0159 & 0.0132 & 0.2300 & 0.9968 & 0.9494 & 0.0206 \\
\hline LabEq & 0.0276 & 0.0396 & 0.1373 & 0.9701 & 0.7897 & 0.0316 \\
\hline Mach & 0.0122 & 0.0315 & 0.2201 & 0.9783 & 0.8799 & 0.0157 \\
\hline Meals & -0.0050 & 0.0231 & 0.3248 & 0.9868 & 0.9466 & -0.0072 \\
\hline MedEq & 0.0238 & 0.0320 & 0.1115 & 0.9778 & 0.7764 & 0.0266 \\
\hline Mines & 0.0113 & 0.0455 & 0.1912 & 0.9641 & 0.8256 & 0.0138 \\
\hline Misc & -0.0054 & 0.0354 & 0.1093 & 0.9743 & 0.7485 & -0.0060 \\
\hline Paper & 0.0129 & 0.0268 & 0.4052 & 0.9830 & 0.9515 & 0.0257 \\
\hline PerSv & -0.0067 & 0.0206 & 0.2311 & 0.9893 & 0.9242 & -0.0087 \\
\hline RlEst & -0.0154 & 0.0161 & 0.2857 & 0.9939 & 0.9567 & -0.0208 \\
\hline Rtail & 0.0026 & 0.0222 & 0.3523 & 0.9876 & 0.9468 & 0.0039 \\
\hline Rubbe & 0.0108 & 0.0437 & 0.2284 & 0.9660 & 0.8487 & 0.0164 \\
\hline Ships & 0.0109 & 0.0545 & 0.2159 & 0.9550 & 0.8134 & 0.0134 \\
\hline Smoke & 0.0297 & 0.0173 & 0.3157 & 0.9926 & 0.9325 & 0.0359 \\
\hline Soda & 0.0243 & 0.0355 & 0.4028 & 0.9742 & 0.9312 & 0.0412 \\
\hline Steel & -0.0001 & 0.0170 & 0.2077 & 0.9929 & 0.9175 & -0.0001 \\
\hline Telcm & 0.0312 & 0.0106 & 0.1499 & 0.9994 & 0.9450 & 0.0363 \\
\hline Toys & -0.0174 & 0.0199 & 0.2335 & 0.9900 & 0.9301 & -0.0234 \\
\hline Trans & 0.0079 & 0.0269 & 0.3153 & 0.9829 & 0.9262 & 0.0119 \\
\hline Txtls & -0.0198 & 0.0293 & 0.4905 & 0.9805 & 0.9492 & -0.0384 \\
\hline Util & 0.0241 & 0.0367 & 0.3122 & 0.9730 & 0.9062 & 0.0351 \\
\hline Whlsl & -0.0029 & 0.0352 & 0.3269 & 0.9745 & 0.9200 & -0.0051 \\
\hline
\end{tabular}


Table 2. Summary Statistics of Expected Returns

Table 2, Panel A [B] reports the time-series average of quarterly cross-sectional distributional summary statistics for the estimated expected log return proxies [realized log returns] at various horizons: 1-, 4-, 8-, and 12-quarters ahead (1Q-, 4Q-, 8Q-, and 12Q-Ahead, respectively) as well as long-term (LT) expected returns. The last two columns of Panel A report time-series averages of the quarterly distributional summary statistics for the spreads between LT (annualized) and 1Q-Ahead (annualized) as well as spreads between 12Q- and 1Q-Ahead (annualized) expected log returns; the last column of Panel B reports summary statistics for the spreads between 12Q- and 1Q-Ahead (annualized) realized log returns. Expected returns proxies at the various horizons are computed based on equation (9) using the estimated coefficients and the implied model parameters of equation (12).

Panel A: Expected log return proxies

\begin{tabular}{lrrrrrrr}
\hline Stat & $\begin{array}{r}\text { 1Q- } \\
\text { Ahead }\end{array}$ & $\begin{array}{r}\text { 4Q- } \\
\text { Ahead }\end{array}$ & $\begin{array}{r}\mathbf{8 Q -} \\
\text { Ahead }\end{array}$ & $\begin{array}{r}\text { 12Q- } \\
\text { Ahead }\end{array}$ & $\begin{array}{r}\text { Long- } \\
\text { Term }\end{array}$ & $\begin{array}{r}\text { LT-1Q } \\
\text { Diff }\end{array}$ & $\begin{array}{r}\text { 12Q-1Q } \\
\text { Diff }\end{array}$ \\
\hline P5 & -0.0776 & -0.2996 & -0.5728 & -0.8216 & -0.0695 & -0.3541 & -0.0225 \\
P25 & -0.0193 & -0.0740 & -0.1401 & -0.1997 & -0.0018 & -0.0164 & -0.0007 \\
Mean & -0.0070 & -0.0257 & -0.0460 & -0.0616 & 0.0061 & 0.0509 & 0.0073 \\
Median & 0.0000 & 0.0016 & 0.0067 & 0.0144 & 0.0133 & 0.0498 & 0.0041 \\
P75 & 0.0163 & 0.0649 & 0.1289 & 0.1913 & 0.0236 & 0.1331 & 0.0134 \\
P95 & 0.0392 & 0.1528 & 0.2981 & 0.4388 & 0.0530 & 0.3989 & 0.0437 \\
StdDev & 0.0426 & 0.1651 & 0.3178 & 0.4597 & 0.0380 & 0.2474 & 0.0233 \\
\hline
\end{tabular}

Panel B: Realized log returns

\begin{tabular}{lrrrrr}
\hline Stat & $\begin{array}{r}1 \mathbf{1 Q}- \\
\text { Ahead }\end{array}$ & $\begin{array}{r}\text { 4Q- } \\
\text { Ahead }\end{array}$ & $\begin{array}{r}\mathbf{8 Q}- \\
\text { Ahead }\end{array}$ & $\begin{array}{r}\text { 12Q- } \\
\text { Ahead }\end{array}$ & $\begin{array}{r}\text { 12Q-1Q } \\
\text { Diff }\end{array}$ \\
\hline P5 & -0.4649 & -1.1193 & -1.7852 & -2.3006 & -1.6395 \\
P25 & -0.1329 & -0.2858 & -0.4197 & -0.5173 & -0.5139 \\
Mean & -0.0156 & -0.0598 & -0.1116 & -0.1478 & 0.0230 \\
Median & 0.0045 & 0.0287 & 0.0639 & 0.0995 & 0.0002 \\
P75 & 0.1274 & 0.2751 & 0.4026 & 0.5043 & 0.5147 \\
P95 & 0.3841 & 0.7465 & 0.9965 & 1.1719 & 1.6948 \\
StdDev & 0.3114 & 0.6635 & 0.9629 & 1.1805 & 1.2106 \\
\hline
\end{tabular}




\section{Table 3. Return Regressions}

Table 3 reports the results of regressions of future realized stock returns, $r_{t+T}$, on expected return proxies, $\mathbb{E}_{t}\left[r_{t+T}\right]$, where $T$ corresponds to 3-, 12-, 24-, or 36-months ahead (3M, 12M, 24M, and 36M, respectively). Columns (5)-(8) include Fama and French (1997) 48 industry fixed effects. Standard errors are two-way cluster robust, clustering by firm and year-quarter, and are reported below the coefficient estimates in parentheses. Levels of significance are indicated by *, **, and *** for $10 \%, 5 \%$, and $1 \%$, respectively.

\begin{tabular}{rcccccccc}
\hline & $(1)$ & $(2)$ & $(3)$ & $(4)$ & $(5)$ & $(6)$ & $(7)$ & $(8)$ \\
\hline \multirow{4}{*}[r_{i,t+1}]{} & $\mathbf{3 M}$ & $\mathbf{1 2 M}$ & $\mathbf{2 4 M}$ & $\mathbf{3 6 M}$ & $\mathbf{3 M}$ & $\mathbf{1 2 M}$ & $\mathbf{2 4 M}$ & $\mathbf{3 6 M}$ \\
& $0.8555^{* * *}$ & $0.7162^{* * *}$ & $0.5954^{* * *}$ & $0.5244^{* * *}$ & $0.8342^{* * *}$ & $0.6852^{* * *}$ & $0.5606^{* * *}$ & $0.4904^{* * *}$ \\
Cons & $(0.092)$ & $(0.055)$ & $(0.036)$ & $(0.027)$ & $(0.074)$ & $(0.046)$ & $(0.031)$ & $(0.025)$ \\
& -0.0062 & -0.0288 & $-0.0611^{* *}$ & $-0.0857^{* * *}$ & 0.0081 & 0.0293 & $0.0657^{*}$ & $0.1013^{*}$ \\
& $(0.011)$ & $(0.021)$ & $(0.027)$ & $(0.031)$ & $(0.012)$ & $(0.026)$ & $(0.040)$ & $(0.055)$ \\
\hline $\mathrm{N}$ & 550,320 & 538,694 & 522,872 & 506,734 & 550,320 & 538,694 & 522,872 & 506,734 \\
$\mathrm{FE}$ & $\mathrm{No}$ & $\mathrm{No}$ & No & No & Yes & Yes & Yes & Yes \\
Adj $R^{2}$ & 0.0120 & 0.0284 & 0.0361 & 0.0403 & 0.0126 & 0.0306 & 0.0405 & 0.0467 \\
\hline
\end{tabular}




\section{Table 4. Future Stock Returns Sorted on Expected Return Estimates}

Table 4 reports the average 3-, 12-, 24-, and 36-months ahead (3M, 12M, 24M, and 36M, respectively) log gross returns (marketadjusted and size-adjusted) for each quintile of our model-estimated expected returns proxy, where quintile portfolios are constructed for each year-quarter from 1986Q1 to 2013Q3. The last four rows report, respectively, the average quintile spread in log gross returns between the $5^{\text {th }}$ and $1^{\text {st }}$ quintiles, the average decile spread in log gross returns between the $10^{\text {th }}$ and $1^{\text {st }}$ deciles, the average quintile spread in returns between the $5^{\text {th }}$ and $1^{\text {st }}$ quintiles, and the average decile spread in returns between the $10^{\text {th }}$ and $1^{\text {st }}$ deciles. All quintile and decile spreads are significantly different from 0 at the $1 \%$ level.

\begin{tabular}{cccccccccc}
\hline & \multicolumn{4}{c}{ Mkt-Adj Log Returns } & \multicolumn{3}{c}{ Size-Adj Log Returns } \\
\hline Quantile & 3M & $\mathbf{1 2 M}$ & $\mathbf{2 4 M}$ & $\mathbf{3 6 M}$ & 3M & $\mathbf{1 2 M}$ & $\mathbf{2 4 M}$ & $\mathbf{3 6 M}$ & $\mathbf{N}$ \\
1 & -0.0864 & -0.3078 & -0.4321 & -0.4358 & -0.0895 & -0.3049 & -0.4209 & -0.4341 & 112,048 \\
2 & -0.0331 & -0.1432 & -0.2327 & -0.2401 & -0.0359 & -0.1522 & -0.2345 & -0.2488 & 112,103 \\
3 & -0.0234 & -0.1007 & -0.1709 & -0.1752 & -0.0272 & -0.1118 & -0.1740 & -0.1806 & 112,096 \\
4 & -0.0136 & -0.0708 & -0.1219 & -0.1263 & -0.0192 & -0.0881 & -0.1319 & -0.1436 & 112,103 \\
5 & -0.0075 & -0.0587 & -0.1024 & -0.0877 & -0.0154 & -0.0874 & -0.1170 & -0.1070 & 112,142 \\
\hline 5-1 Spread & 0.0790 & 0.2491 & 0.3297 & 0.3481 & 0.0741 & 0.2175 & 0.3039 & 0.3271 & \\
10-1 Spread & 0.1094 & 0.3286 & 0.4240 & 0.4483 & 0.1040 & 0.2923 & 0.3982 & 0.4407 \\
5-1 Spread (Returns) & 0.0389 & 0.1109 & 0.2305 & 0.3551 & 0.0359 & 0.0998 & 0.2069 & 0.3163 \\
\end{tabular}




\section{Table 5. IV Estimation Results}

Table 5, Panel A reports summary statistics for the estimated coefficients on $b m_{t}$ and roet of equation (12) as well as the implied parameters of the model, similar to Table 1. The coefficients are estimated by pooled IV using the last quarter's log return on equity, $r_{0 e_{-1}}$, as the instrument for the current quarter's log return on equity, roe $e_{t}$ The fifth column reports summary statistics on the first-stage $F$-statistic $(F)$ from the IV estimation. All other aspects of the estimation are the same as in Table 1. Panel B reports the return regression tests of Table 3 using the IV-estimated expected return proxies. Standard errors are two-way cluster robust (firm and year-quarter), and levels of significance are indicated by *, **, and ${ }^{* * *}$ for $10 \%, 5 \%$, and $1 \%$, respectively.

Panel A: Overall Parameter Estimates

\begin{tabular}{|c|c|c|c|c|c|c|c|}
\hline & \multicolumn{4}{|c|}{ Regression Coefficients } & \multicolumn{3}{|c|}{ Implied Parameters } \\
\hline & Cons & $b m$ & roe & $F$ & $\kappa$ & $\omega$ & $\mu$ \\
\hline P5 & -0.0202 & 0.0048 & 0.1265 & 77.18 & 0.9516 & 0.8695 & -0.0713 \\
\hline $\mathrm{P} 25$ & -0.0061 & 0.0171 & 0.3270 & 346.50 & 0.9744 & 0.9377 & -0.0075 \\
\hline Mean & 0.0036 & 0.0275 & 0.6038 & 1555.04 & 0.9815 & 0.9498 & 0.0080 \\
\hline Median & 0.0045 & 0.0269 & 0.5303 & 742.01 & 0.9830 & 0.9628 & 0.0133 \\
\hline P75 & 0.0124 & 0.0353 & 0.7759 & 1780.20 & 0.9929 & 0.9804 & 0.0287 \\
\hline P95 & 0.0272 & 0.0580 & 1.3875 & 4891.45 & 0.9999 & 0.9999 & 0.0758 \\
\hline Std & 0.0154 & 0.0163 & 0.4148 & 2861.71 & 0.0151 & 0.0653 & 0.0693 \\
\hline
\end{tabular}

Panel B: Return Regressions

\begin{tabular}{|c|c|c|c|c|c|c|c|c|}
\hline & (1) & $(2)$ & $(3)$ & (4) & (5) & (6) & $(7)$ & (8) \\
\hline & $3 \mathrm{M}$ & $12 \mathrm{M}$ & $24 \mathrm{M}$ & $36 \mathrm{M}$ & $3 \mathrm{M}$ & $12 \mathrm{M}$ & $24 \mathrm{M}$ & $36 \mathrm{M}$ \\
\hline$\hat{\mathbb{E}}\left[r_{i, t+1}\right]$ & $\begin{array}{c}0.6102^{* * *} \\
(0.069)\end{array}$ & $\begin{array}{c}0.5006^{* * *} \\
0.000\end{array}$ & $\begin{array}{c}0.4056^{* * *} \\
(0.025)\end{array}$ & $\begin{array}{c}0.3485^{* * *} \\
(0.019)\end{array}$ & $\begin{array}{c}0.5866^{* * *} \\
(0.059)\end{array}$ & $\begin{array}{c}0.4742^{* * *} \\
(0.034)\end{array}$ & $\begin{array}{c}0.3791^{* * *} \\
(0.022)\end{array}$ & $\begin{array}{c}0.3231^{* * *} \\
(0.016)\end{array}$ \\
\hline Cons & $\begin{array}{c}-0.0074 \\
(0.011)\end{array}$ & $\begin{array}{c}-0.0331 \\
(0.021)\end{array}$ & $\begin{array}{c}-0.0683^{* *} \\
(0.027)\end{array}$ & $\begin{array}{c}-0.0951^{* * *} \\
(0.031)\end{array}$ & $\begin{array}{c}0.0107 \\
(0.012)\end{array}$ & $\begin{array}{l}0.0384 \\
(0.025)\end{array}$ & $\begin{array}{c}0.0820^{* *} \\
(0.040)\end{array}$ & $\begin{array}{c}0.1248^{* *} \\
(0.055)\end{array}$ \\
\hline $\mathrm{N}$ & 550,320 & 538,694 & 522,872 & 506,734 & 550,320 & 538,694 & 522,872 & 506,734 \\
\hline $\mathrm{FE}$ & No & No & No & No & Yes & Yes & Yes & Yes \\
\hline $\operatorname{Adj} R^{2}$ & 0.0126 & 0.0288 & 0.0351 & 0.0377 & 0.0134 & 0.0319 & 0.0410 & 0.0459 \\
\hline
\end{tabular}




\section{Table 6. Annual Data OLS Estimation Results}

Table 6, Panel A reports summary statistics for the estimated coefficients on $b m_{t}$ and $r o e_{t}$ of equation (12) as well as the implied parameters of the model, similar to Table 1 . The coefficients are estimated by pooled OLS within industry and on an annual basis, at the end of June of each year, using the most recent publicly available financial data on book values and earnings to avoid look-ahead bias. The estimation pools all firms within the same Fama and French (1997) 48 industry classification across time, with a burn-in of 15 years of data for a given industry. Panel B reports the return regression tests of Table 3 using the annually estimated expected return proxies. Standard errors are two-way cluster robust (firm and year), and levels of significance are indicated by $*, * *$, and $* * *$ for $10 \%, 5 \%$, and $1 \%$, respectively.

Panel A: Overall Parameter Estimates

\begin{tabular}{|c|c|c|c|c|c|c|}
\hline & \multicolumn{3}{|c|}{ Regression Coefficients } & \multicolumn{3}{|c|}{ Implied Parameters } \\
\hline & Cons & $b m$ & roe & $\kappa$ & $\omega$ & $\mu$ \\
\hline $\mathrm{P} 5$ & -0.0430 & 0.0282 & 0.1415 & 0.8590 & 0.5704 & -0.0627 \\
\hline $\mathrm{P} 25$ & 0.0021 & 0.0630 & 0.2217 & 0.8982 & 0.7165 & 0.0097 \\
\hline Mean & 0.0407 & 0.0865 & 0.3148 & 0.9227 & 0.7721 & 0.0572 \\
\hline Median & 0.0477 & 0.0799 & 0.2743 & 0.9294 & 0.7861 & 0.0674 \\
\hline P75 & 0.0725 & 0.1108 & 0.3692 & 0.9464 & 0.8449 & 0.1075 \\
\hline P95 & 0.1274 & 0.1496 & 0.5986 & 0.9816 & 0.9292 & 0.1713 \\
\hline Std & 0.0514 & 0.0379 & 0.1590 & 0.0383 & 0.1092 & 0.0743 \\
\hline
\end{tabular}

Panel B: Return Regressions

\begin{tabular}{|c|c|c|c|c|c|c|}
\hline & (1) & $(2)$ & (3) & $(4)$ & $(5)$ & (6) \\
\hline & $12 \mathrm{M}$ & $24 \mathrm{M}$ & $36 \mathrm{M}$ & $12 \mathrm{M}$ & $24 \mathrm{M}$ & $36 \mathrm{M}$ \\
\hline$\hat{\mathbb{E}}\left[r_{i, t+1}\right]$ & $\begin{array}{c}0.5832^{* * *} \\
(0.091)\end{array}$ & $\begin{array}{c}0.5132^{* * *} \\
(0.067)\end{array}$ & $\begin{array}{c}0.4620^{* * *} \\
(0.047)\end{array}$ & $\begin{array}{c}0.5450 * * * \\
(0.086)\end{array}$ & $\begin{array}{c}0.4729 * * * \\
(0.063)\end{array}$ & $\begin{array}{c}0.4234^{* * *} \\
(0.044)\end{array}$ \\
\hline Cons & $\begin{array}{c}-0.0064 \\
(0.029)\end{array}$ & $\begin{array}{r}-0.0131 \\
(0.041)\end{array}$ & $\begin{array}{c}-0.0149 \\
(0.049)\end{array}$ & $\begin{array}{l}0.0458 \\
(0.040)\end{array}$ & $\begin{array}{c}0.0960^{*} \\
(0.054)\end{array}$ & $\begin{array}{c}0.1458^{* *} \\
(0.067)\end{array}$ \\
\hline $\mathrm{N}$ & 173,802 & 170,044 & 166,257 & 173,802 & 170,044 & 166,257 \\
\hline $\mathrm{FE}$ & No & No & No & Yes & Yes & Yes \\
\hline $\operatorname{Adj} R^{2}$ & 0.0158 & 0.0220 & 0.0261 & 0.0174 & 0.0250 & 0.0308 \\
\hline
\end{tabular}




\section{Table 7. Expected Returns Estimates}

Table 7, Panel A reports summary statistics for the estimated coefficients and the implied model parameters of equations (12) and (20), similar to Table 1 . The coefficients are estimated using seemingly unrelated regressions, run recursively, within industry, and at the end of March, June, September, and December each year, using the most recent publicly available financial data on book values and earnings to avoid look-ahead bias. The estimation pools all firms within the same Fama and French (1997) 48 industry classification across time, with a burn-in of 15 years of data for a given industry. Panel B reports the return regression tests of Table 3 using the quarterly estimated expected net return proxies. Standard errors are two-way cluster robust (firm and year-quarter), and levels of significance are indicated by $*, * *$, and $* * *$ for $10 \%, 5 \%$, and $1 \%$, respectively.

Panel A: Overall Parameter Estimates

\begin{tabular}{|c|c|c|c|c|c|c|c|c|}
\hline & \multicolumn{4}{|c|}{ Regression Coefficients } & \multicolumn{3}{|c|}{ Implied Parameters } & \multirow[b]{2}{*}{$\hat{\mathbb{E}}\left[R_{i, t+1}\right]$} \\
\hline & Cons & $b m$ & roe & $A$ & $\kappa$ & $\omega$ & $\mu$ & \\
\hline $\mathrm{P} 5$ & -0.0171 & 0.0114 & 0.0016 & 1.0169 & 0.9531 & 0.3703 & -0.0199 & 0.0075 \\
\hline P25 & -0.0007 & 0.0256 & 0.0497 & 1.0248 & 0.9700 & 0.6593 & -0.0008 & 0.0228 \\
\hline Mean & 0.0101 & 0.0330 & 0.1258 & 1.0346 & 0.9767 & 0.7230 & 0.0116 & 0.0289 \\
\hline Median & 0.0115 & 0.0314 & 0.0871 & 1.0334 & 0.9784 & 0.7595 & 0.0124 & 0.0291 \\
\hline P75 & 0.0207 & 0.0397 & 0.1498 & 1.0426 & 0.9842 & 0.8366 & 0.0247 & 0.0338 \\
\hline P95 & 0.0346 & 0.0564 & 0.4241 & 1.0563 & 0.9986 & 0.9552 & 0.0409 & 0.0452 \\
\hline Std & 0.0155 & 0.0136 & 0.1458 & 0.0126 & 0.0135 & 0.1865 & 0.0193 & 0.0081 \\
\hline
\end{tabular}

Panel B: Return Regressions

\begin{tabular}{|c|c|c|c|c|c|c|c|c|}
\hline & (1) & $(2)$ & (3) & $(4)$ & (5) & (6) & $(7)$ & (8) \\
\hline & $3 \mathrm{M}$ & $12 \mathrm{M}$ & $24 \mathrm{M}$ & $36 \mathrm{M}$ & $3 \mathrm{M}$ & $12 \mathrm{M}$ & $24 \mathrm{M}$ & $36 \mathrm{M}$ \\
\hline$\hat{\mathbb{E}}\left[r_{i, t+1}\right]$ & $\begin{array}{c}0.5973^{* * *} \\
(0.084)\end{array}$ & $\begin{array}{c}0.4361^{* * *} \\
(0.058)\end{array}$ & $\begin{array}{c}0.4129 * * * \\
(0.047)\end{array}$ & $\begin{array}{c}0.3856^{* * *} \\
(0.037)\end{array}$ & $\begin{array}{c}0.5986^{* * *} \\
(0.089)\end{array}$ & $\begin{array}{c}0.4997^{* * *} \\
(0.056)\end{array}$ & $\begin{array}{c}0.4748^{* * *} \\
(0.049)\end{array}$ & $\begin{array}{c}0.4368 * * * \\
(0.043)\end{array}$ \\
\hline Cons & $\begin{array}{l}0.0173 \\
(0.011)\end{array}$ & $\begin{array}{c}0.1372^{* * *} \\
(0.023)\end{array}$ & $\begin{array}{c}0.2679 * * * \\
(0.029)\end{array}$ & $\begin{array}{c}0.3882^{* * *} \\
(0.036)\end{array}$ & $\begin{array}{c}0.0217^{*} \\
(0.011)\end{array}$ & $\begin{array}{c}0.1243^{* * *} \\
(0.026)\end{array}$ & $\begin{array}{c}0.2658^{* * *} \\
(0.050)\end{array}$ & $\begin{array}{c}0.4240 * * * \\
(0.076)\end{array}$ \\
\hline $\mathrm{N}$ & 550,320 & 538,694 & 522,872 & 506,734 & 550,320 & 538,694 & 522,872 & 506,734 \\
\hline $\mathrm{FE}$ & No & No & No & No & Yes & Yes & Yes & Yes \\
\hline $\operatorname{Adj} R^{2}$ & 0.0030 & 0.0040 & 0.0051 & 0.0056 & 0.0034 & 0.0063 & 0.0077 & 0.0081 \\
\hline
\end{tabular}


Table 8. Comparison with Factor Model Based Estimates

Table 8, Panel A reports the return regression tests of Table 3, comparing the proxies of expected quarterly returns from estimating equations (12) and (20) to the proxies of expected quarterly returns from CAPM, Fama and French (1993) three-factor model, and the three-factor model augmented by the UMD momentum factor (Fama and French, 1996). Factor returns are obtained from Ken French's data library. Coefficients are obtained from pooled regressions of one-quarter ahead realized returns on ex ante proxies of expected quarterly returns. Standard errors are two-way cluster robust (firm and year-quarter). Panel B reports the portfolio sort tests of Table 4 by forming quarterly quintile and decile portfolios of the four alternative expected returns proxies. OLS standard errors are used in significance tests. For both panels, analyses are conducted for the subset of firm year-quarter non-missing observations across all four proxies, and levels of significance are indicated by *,**, and $* * *$ for $10 \%, 5 \%$, and $1 \%$, respectively.

Panel A: Return Regressions

\begin{tabular}{rcccccccc}
\hline & $(1)$ & $(2)$ & $(3)$ & $(4)$ & $(5)$ & $(6)$ & $(7)$ & $(8)$ \\
& Lyle-Wang & CAPM & FF3 & FF4 & Lyle-Wang & CAPM & FF3 & FF4 \\
\hline$\hat{\mathbb{E}}\left[r_{i, t+1}\right]$ & $0.5620^{* * *}$ & -0.7034 & $-0.6133^{* *}$ & $-0.5240^{* * *}$ & $0.5577^{* * *}$ & $-0.7463^{*}$ & $-0.6057^{* *}$ & $-0.5159^{* * *}$ \\
& $(0.082)$ & $(0.437)$ & $(0.252)$ & $(0.197)$ & $(0.088)$ & $(0.439)$ & $(0.253)$ & $(0.196)$ \\
Cons & $0.0209^{* *}$ & $0.0572^{* * *}$ & $0.0564^{* * *}$ & $0.0525^{* * *}$ & $0.0230^{* *}$ & $0.0609^{* * *}$ & $0.0616^{* * *}$ & $0.0573^{* * *}$ \\
& $(0.011)$ & $(0.015)$ & $(0.014)$ & $(0.013)$ & $(0.011)$ & $(0.016)$ & $(0.014)$ & $(0.013)$ \\
\hline $\mathrm{N}$ & 485,222 & 485,222 & 485,222 & 485,222 & 485,222 & 485,222 & 485,222 & 485,222 \\
$\mathrm{FE}$ & No & No & No & No & Yes & Yes & Yes & Yes \\
Adj $R^{2}$ & 0.0027 & 0.0030 & 0.0031 & 0.0031 & 0.0032 & 0.0040 & 0.0037 & 0.0036 \\
\hline
\end{tabular}

Panel B: Portfolio Sorts

\begin{tabular}{|c|c|c|c|c|c|c|c|c|c|}
\hline \multirow[b]{2}{*}{ Quantile } & \multicolumn{4}{|c|}{ Mkt-Adj Returns } & \multicolumn{4}{|c|}{ Size-Adj Returns } & \multirow[b]{2}{*}{$\mathbf{N}$} \\
\hline & Lyle-Wang & CAPM & FF3 & FF4 & Lyle-Wang & CAPM & FF3 & FF4 & \\
\hline 1 & -0.0067 & 0.0163 & 0.0195 & 0.0207 & -0.0101 & 0.0110 & 0.0121 & 0.0128 & 98,693 \\
\hline 2 & 0.0033 & 0.0156 & 0.0120 & 0.0123 & -0.0001 & 0.0094 & 0.0061 & 0.0064 & 98,745 \\
\hline 3 & 0.0084 & 0.0118 & 0.0096 & 0.0083 & 0.0039 & 0.0064 & 0.0040 & 0.0028 & 98,735 \\
\hline 4 & 0.0150 & 0.0047 & 0.0062 & 0.0059 & 0.0086 & -0.0006 & 0.0011 & 0.0012 & 98,745 \\
\hline 5 & 0.0310 & -0.0012 & 0.0032 & 0.0031 & 0.0201 & -0.0060 & -0.0010 & -0.0012 & 98,784 \\
\hline 5-1 Spread & $0.0377^{* * *}$ & -0.0175 & $-0.0164^{*}$ & $-0.0176^{* *}$ & $0.0302^{* * *}$ & -0.0170 & $-0.0131^{*}$ & $-0.0140 * *$ & \\
\hline 10-1 Spread & $0.0538^{* * *}$ & -0.0143 & $-0.0197^{*}$ & $-0.0207^{* *}$ & $0.0449 * * *$ & -0.0146 & $-0.0155^{*}$ & $-0.0160 * *$ & \\
\hline
\end{tabular}




\section{Table 9. Market-Level Prediction}

Table 9, Panel A reports Clark and McCracken (2001) significance levels $[p(C M)]$ and out-ofsample $R^{2}\left(R_{o s}^{2}\right)$ produced by our aggregate predictor and two versions of the forecaster proposed by Kelly and Pruitt (2013) ["K\&P (2013)"]. All three predictors form expected returns from 1986Q1 to 2013Q3. The notation " $<x$ " indicates the smallest significance level for which the ENC-NEW statistic, testing a given predictor against the historical mean of the target series, exceeds the critical value, and are obtained from Clark and McCracken (2000). Column (2) considers a version of K\&P (2013)'s forecaster, adapted to forecast quarterly returns, using quarterly returns from 1930-2013 and a 50-year training sample ending in 1980; column (3) considers a variant of this forecaster but using quarterly returns from 1971-2013 with a 15-year training sample ending in 1986. Out-of-sample $R^{2}$ is defined as $R_{o s}^{2}=1-\frac{\sum_{t=1}^{T}\left(r_{t}-\hat{r}_{t}\right)^{2}}{\sum_{t=1}^{T}\left(r_{t}-\bar{r}_{t}\right)^{2}}$ for each forecaster $\left\{\hat{r}_{t}\right\}_{1}^{T}$ and $\bar{r}_{t}$ is the historical average estimated through $t-1$. Panel B reports univariate return regressions of 1-quarter ahead log returns on expected log return proxies. Levels of significance are indicated by ${ }^{*},{ }^{* *}$, and $* * *$ for $10 \%, 5 \%$, and $1 \%$, respectively.

Panel A: Clark and McCracken (2001) p-Values and Out-of-Sample $R^{2}$

\begin{tabular}{lccc}
\hline & $(1)$ & $(2)$ & $(3)$ \\
& Lyle-Wang & K\&P $(2013)$ & K\&P $(2013)$ \\
& & $1930-2013$ Data & $1971-2013$ Data \\
\hline$p(C M)$ & $<0.01$ & $<0.01$ & $<0.05$ \\
$R_{\text {os }}^{2}$ & $0.62 \%$ & $4.78 \%$ & $0.53 \%$ \\
\hline
\end{tabular}

Panel B: Return Regressions

\begin{tabular}{lccc}
\hline & $(1)$ & $(2)$ & $(3)$ \\
& Lyle-Wang & K\&P $(2013)$ & K\&P (2013) \\
& & 1930-2013 Data & 1971-2013 Data \\
\hline$\hat{\mathbb{E}}\left[r_{i, t+1}\right]$ & $0.4936^{*}$ & $1.3518^{* *}$ & 0.4512 \\
& $(0.260)$ & $(0.555)$ & $(0.375)$ \\
Cons & 0.0096 & -0.0209 & 0.0128 \\
& $(0.014)$ & $(0.022)$ & $(0.016)$ \\
\hline$N$ & 111 & 111 & 0.013 \\
\hline$R^{2}$ & 0.032 & 0.052 & \\
\hline
\end{tabular}

